\title{
The impact of trade reporting and central clearing on CDS price informativeness
}

\section{Article}

\section{Accepted Version}

Creative Commons: Attribution-Noncommercial-No Derivative Works 4.0

Marra, M., Yu, F. and Zhu, L. (2019) The impact of trade reporting and central clearing on CDS price informativeness. Journal of Financial Stability, 43. pp. 130-145. ISSN 15723089 doi: https://doi.org/10.1016/j.jfs.2019.07.002 Available at https://centaur.reading.ac.uk/84785/

It is advisable to refer to the publisher's version if you intend to cite from the work. See Guidance on citing.

To link to this article DOI: http://dx.doi.org/10.1016/j.jfs.2019.07.002

Publisher: Elsevier

All outputs in CentAUR are protected by Intellectual Property Rights law, including copyright law. Copyright and IPR is retained by the creators or other copyright holders. Terms and conditions for use of this material are defined in the End User Agreement.

\section{www.reading.ac.uk/centaur}

\section{CentAUR}

Central Archive at the University of Reading

Reading's research outputs online 


\title{
The impact of trade reporting and central clearing
}

\section{on CDS price informativeness}

\author{
Miriam Marra $^{a}$
}

Fan $\mathrm{Yu}^{\mathrm{b}}$

$\mathrm{Lu} \mathrm{Zhu}^{\mathrm{c}}$

a ICMA Centre, Henley Business School, University of Reading, Whiteknight Campus, Reading, UK; m.marra@icmacentre.ac.uk.

${ }^{\mathrm{b}}$ Robert Day School of Economics and Finance, Claremont McKenna College, Claremont, California, USA; fyu@cmc.edu.

${ }^{c}$ College of Business Administration, California State University Long Beach, Long Beach, California, USA; lu.zhu@ csulb.edu (Corresponding author).

\begin{abstract}
We find that the magnitude of unique credit default swap (CDS) market information (constructed to be orthogonal to contemporaneous and lagged stock returns) declined after recent reforms that increased the level of post-trade regulatory and market transparency for CDSs. Around the same reforms, the ability of this CDS-unique information to predict future stock returns decreased. These results suggest the CDS market has become less of a "hidden" trading venue for informed investors since central clearing and trade reporting started.
\end{abstract}

Keywords: Credit default swap; Post-trade transparency; Central clearing; Trade reporting; Informed trading.

JEL classification: G12; G13; G14 


\section{Introduction}

Prior to the global financial crisis (GFC), the credit default swap (CDS) market was considered an opaque, over-the-counter (OTC) market, in part because transaction-level data were not easily available to regulators and participants. In the aftermath of the GFC, several changes were introduced in the CDS market. In September 2009, the G20 leaders called for global improvements in the transparency and regulatory oversight of OTC derivatives via a move towards central clearing and trade reporting to repositories. In July 2010, the US Congress passed the Dodd-Frank Wall Street Reform and Consumer Protection Act (DFA) that, in its Title VII, mandates central counterparty (CCP) clearing, post-execution trade reporting to a swap data repository (SDR), SDR provision of data to regulators, and insidertrading prohibition for several eligible OTC derivatives, including CDSs. Under the DFA, the Securities and Exchange Commission (SEC) is responsible for determining the specific rules for eligible single-name CDSs to be cleared via a CCP and reported mandatorily to an SDR. ${ }^{1}$

However, even before the passage of the DFA in 2010 and the SEC's approval of relevant rules in 2015 and 2016, the CDS market structure was already undergoing important changes, triggered by the GFC events. In October 2008, a single repository, the Depository Trust \& Clearing Corporation (DTCC), began: (i) registering CDS trades; (ii) making data reported by traders under a voluntary reporting regime available to the SEC and other relevant authorities; and (iii) publishing weekly aggregate transaction and position data for top single-name CDSs. In December 2009, Intercontinental Exchange Clear Credit (ICECC) began its voluntary central clearing service for North American single-name CDSs and public dissemination of daily volumes and the number of trades of its clearing activities. ${ }^{2}$ Altogether, 159 reference

\footnotetext{
${ }^{1}$ As additional evidence of regulators' increasing attention towards the CDS market, in May 2009 the SEC filed the first insider trading case involving CDSs. Information about this insider trading case is available at the SEC link: https://www.sec.gov/news/press/2009/2009-102.htm.

${ }^{2}$ When a CDS position between two counterparties that are members of ICECC is submitted for clearing, the original contract is extinguished and replaced by two new contracts where ICECC acts as the counterparty to the original buyer and
} 
entities began central clearing on ICECC at various points up to the end of 2013. This central clearing activity has increased the level of transparency in the CDS market.

In this paper, we focus on the impact of these changes on informed trading in the CDS market. The stock price and CDS premium of a firm are exposed to the same fundamental shocks to its future cash flows. However, because of the differences in market structure and the presence of market frictions, informed investors may choose to trade in only one of these two securities, which would lead to earlier price discovery in the market chosen as the venue for informed trading.

A number of papers study the lead-lag linkage between the CDS and stock markets. Acharya and Johnson (2007) find that changes in CDS premium negatively predict stock returns for a sample of 79 US firms during the pre-GFC period, from January 2001 to October 2004. Furthermore, they show that the intensity of the CDS-to-stocks information flow is stronger if the firm has experienced credit events and has a greater number of banking relationships. The authors interpret this evidence in favor of insider trading in the CDS market by banks that exploit their private information obtained from lending relationships. Qiu and Yu (2012) confirm the Acharya and Johnson (2007) results and show that the CDS-to-stocks information flow is stronger when the existing number of dealers providing quotes (proxying for the degree of asymmetric information) is larger. A CDS dealer with more information is more likely to offer quotes to others, as better information allows them to set the quotes correctly without fearing being “picked off” by other informed traders. These two studies on CDS price informativeness use data prior to the GFC.

seller. As a result, the creditworthiness and liquidity of ICECC are substituted for those of the original counterparties. Given its prominent role, in July 2011, ICECC came under the regulation and supervision of the Commodity Futures Trading Commission (CFTC) and the SEC. On 18 July 2012, the Financial Stability Oversight Council designated ICECC as a systemically important financial market utility. Further information is provided in the ICECC documents: https://www.theice.com/publicdocs/Central Clearing Reducing Systemic Risk.pdf and https://www.theice.com/publicdocs/clear_credit/ICEClearCredit_DisclosureFramework.pdf . 
In this paper, we test whether the introduction of central clearing and reporting of CDS trades have changed the level of informativeness of CDS prices. We follow Acharya and Johnson (2007) in estimating the "CDS innovation," which represents CDS-unique information orthogonal to contemporaneous and lagged stock returns by construction. First, to be sure that the estimated CDS innovations actually represent information rather than just illiquidity and noise, we show that they can be used to predict future stock returns. In particular, we see that positive CDS innovations, which reflect firm-specific bad news, can predict future stock returns in the proximity of credit events, but their predictability fell after the DTCC reporting began and central clearing started for the cleared reference entities. Second, by performing panel data regressions with DTCC and central clearing event dummies, we find that the magnitude of unique information incorporated in positive CDS innovations fell significantly around these events as well. Our results therefore suggest an unintended consequence of mandating greater transparency in the CDS market - it can push informed traders away from the CDS market and reduce its price discovery role and contribution to the efficiency of related markets.

Past literature shows that while a total lack of transparency is not desirable, full transparency may deter traders from acquiring information and dissuade informed market participants from trading (see, among others, Grossman and Stiglitz, 1980; Pagano and Röell, 1996; and Naik et al., 1999). The results from the empirical literature in this area tend to support the conjecture that greater transparency helps improve market liquidity: see, for example, Bessembinder et al. (2006), Edwards et al. (2007), and Goldstein et al. (2007) for the effect of TRACE (Trade Reporting and Compliance Engine) introduction on corporate bond transaction costs.

More closely related to our paper is Loon and Zhong (2014), who show that voluntary central clearing of single-name CDS is associated with greater market liquidity. Loon and Zhong (2016) further find that liquidity improves in the index CDS market following the public 
dissemination of real-time trade reports mandated by the DFA reforms. Pereira Da Silva et al. (2018) argue that central clearing enhances the overall quality of the CDS market. Improved liquidity and quality of the market could be attributed to greater post-trade transparency reducing the threat of informed trading to dealers. Our paper complements this literature, as it provides evidence consistent with a decline in informed trading in the single-name CDS market, after the start of DTCC disclosure and ICECC voluntary central clearing. To the extent that informed trading plays an important role in incorporating information into prices, requiring greater transparency could hinder the price discovery process in the CDS market, which seems likely if informed traders who previously traded in the CDS market are now choosing to trade more opaque products such as CDS options. ${ }^{3}$

We develop our research hypotheses in Section 2 and explain the data and methodologies used to test them in Sections 3 to 6. In Appendix A, we review the reforms and the changes in market structure and information disclosure for single-name CDS, introduced in the US since 2008.

\section{Hypothesis development}

In the aftermath of the GFC, well before the DFA started being implemented and the SEC final rules were published in 2015, the introduction of the DTCC data disclosure and the ICECC central clearing sent a clear signal to informed investors that the single-name CDS market was about to change: more transparency would be introduced to achieve better monitoring and reduce the likelihood of financial instability and market abuses. Overall, financial institutions have voiced significant concerns over the development of CDS

\footnotetext{
${ }^{3}$ It is possible that informed trading in the single-name CDS market has already started migrating to CDS options. As the Financial Times reports, the trading in CDS index option "has increased dramatically in recent years partly because - unlike credit default swaps themselves - the instruments are not required to be centrally cleared under new rules aimed at preventing a rerun of the financial crisis, according to traders" (Alloway, 2014). In 2014, an average of $\$ 60$ billion of CDS index options were exchanged per week - up from about $\$ 2$ billion traded per month back in 2005, according to data from the DTCC. Currently, no CDS option can be centrally cleared because of the difficulty of calculating margin requirements on these products.
} 
transparency reforms and the optimal amount of "regulatory" and "market" post-trade transparency for CDSs. Some bank-dealers and their industry association, the International Swaps and Derivatives Association (ISDA), argued that while regulatory reporting is a powerful tool, public reporting could harm the market if the disclosed information triggered speculative trading and market instability. The SEC also warned that a regulator's inability to protect the confidentiality of the data could decrease the profits realized by informed traders and hinder the price discovery role of CDSs.

Since October 31, 2008, the DTCC's Trade Information Warehouse (henceforth, DTCC-TIW) has disseminated trade-level information about single-name CDS transactions to regulators and weekly aggregate information for the most popular contracts to market participants. We argue that the DTCC-TIW offers both "regulatory" and "market" transparency. In terms of "regulatory" transparency, SEC can examine transaction information on single-name CDSs traded by US counterparties or written on a US reference entity at any time, although these data are updated only weekly. In terms of "market" transparency, the DTCC discloses the weekly aggregate gross notional and the aggregate net notional amounts outstanding, as well as the number of CDS contracts on reference entities for the top 1,000 reference entities on its website. So far, the DTCC-TIW serves as a baseline for CDS regulatory and market transparency, which may lower informed trading because the disclosure may reduce the information advantage of informed traders and increase the likelihood that any illegal insider trading is detected. Therefore, we expect a lower level of informed trading in the single-name CDS market after the reporting of transactions began in the DTCC-TIW.

In addition, ICECC central clearing, which began in December 2009, improves upon the baseline DTCC-TIW market transparency by disclosing single-name CDS trading activities (of each cleared reference entity) available at a higher (daily) frequency. Moreover, it improves upon the baseline regulatory transparency by giving regulators close to a real-time 
access to full information on cleared single-name CDS trades. In other words, while the DTCC-TIW publishes single-name CDS open positions and trading activity only on a weekly basis and for top-reference entities, ICECC publishes data on all its cleared contracts at a daily frequency. Appendix A provides a more detailed summary of the DTCC-TIW reporting and ICECC central clearing. We expect that these improvements in post-trade transparency would further reduce the presence of informed trading in the CDS market.

Thus, we state the main hypothesis of our paper as follows:

H1: The higher transparency introduced by the post-crisis reforms (i.e., the start of trade reporting and disclosure by the DTCC and the introduction of voluntary central clearing by ICECC) reduces the level of informed trading in the CDS market.

We test this hypothesis by looking at two important implications.

Stock market analysts and investors are attuned to the CDS market as an alternative source of information, particularly one that is efficient in anticipating bad news about individual firms. The literature has provided a good deal of evidence on this. Acharya and Johnson (2007) show that CDS spread changes can predict stock returns, but are more sensitive to bad than to good news. Zhang and Zhang (2013), Batta et al. (2016) and Kryzanowski et al. (2017) find that the CDS market efficiently anticipates negative earnings surprises. Norden (2017) also observes that the CDS market quickly and accurately incorporates public and private information prior to negative rating events. ${ }^{4}$

\footnotetext{
${ }^{4}$ In addition, Norden and Weber (2004) document the early reaction of the CDS market to announcements of credit rating downgrades. Ni and Pan (2011) find that CDS premium changes can predict stock returns up to a few days, and the pattern of predictability is driven mostly by firms that experience adverse shocks in the CDS market. Berndt and Ostrovnaya (2014) find significant information flow from the CDS market to the stock and options markets for high-yield firms. Marsh and Wagner (2015) show that stocks lead CDS in incorporating general macro news, while CDS premium impound firm-specific bad news before stock prices do. Lee, Naranjo, and Sirmans (2014) and Marra (2017) find that the CDS market contains incremental information relative to the stock market with spillover effects, respectively, from CDS to stock return momentum, and from CDS to stock bid-ask spreads. Bai et al. (2017) find that the introduction of CDS enhances the amount of firm-specific information impounded in stock prices by examining the relation between CDS trading and stock return
} 
Therefore, we test the following sub-hypotheses:

Hla: By reducing informed trading, higher transparency in the CDS market decreases the flow of bad news into the stock market.

H1b: By reducing informed trading, higher transparency in the CDS market decreases the magnitude of bad news contained in CDS spreads.

\section{Data and proxy of CDS price informativeness}

Our main source of CDS pricing data is Markit. We study a large sample of five-year CDS contracts written on 744 US reference entities over the sample period of January 2001 to December 2013. ${ }^{5}$ In Table 1, we report the dates when voluntary central clearing on ICECC began for a subset of these reference entities. The total number of CDS contracts cleared by ICECC at the end of 2013 is 159 . Table 1 provides further information on the reference entities, their sectors, and both the announcement and implementation dates of central clearing. While these contracts have a mixture of centrally cleared (on a voluntary basis) and bilaterally settled transactions after their central clearing start dates, the remaining contracts have exclusively bilateral transactions throughout the sample period.

synchronicity. Lee, Naranjo, and Velioglu (2018) find that CDS returns predict stock returns, particularly their idiosyncratic component, and that the jumps appearing in CDS premium around rating events also significantly predict stock returns.

${ }^{5}$ This is essentially the Batta et al. (2016) CDS sample extended from 2010 to the end of 2013. Since we use the CDS premium to perform time-series regressions, we maintain the requirement that firms in our sample must have at least 252 daily observations of the five-year CDS premium. 
Table 1 ICECC central-clearing dates and centrally-cleared CDS contracts

\begin{tabular}{|c|c|c|c|}
\hline $\begin{array}{c}\text { Event date } \\
\text { (start of ICECC central } \\
\text { clearing) }\end{array}$ & $\begin{array}{c}\text { Number of } \\
\text { CDSs starting } \\
\text { central clearing }\end{array}$ & $\begin{array}{c}\text { Reference entities starting } \\
\text { central clearing }\end{array}$ & $\begin{array}{c}\text { Cumulative } \\
\text { number of } \\
\text { centrally-cleared } \\
\text { CDSs }\end{array}$ \\
\hline $21 / 12 / 2009$ & 3 & $\begin{array}{l}\text { American Electric Power Co., Constellation } \\
\text { Energy Group, Dominion Resources }\end{array}$ & 3 \\
\hline $11 / 01 / 2010$ & 3 & $\begin{array}{l}\text { FirstEnergy, Progress Energy, Sempra } \\
\text { Energy }\end{array}$ & 6 \\
\hline $01 / 02 / 2010$ & 2 & AT\&T, Verizon Communications & 8 \\
\hline $15 / 02 / 2010$ & 14 & $\begin{array}{l}\text { Arrow Electronics, Caterpillar, CSX Corp., } \\
\text { Deere \& Co., Goodrich Corp., Honeywell } \\
\text { International, Ingersoll-Rand Co., Lockheed } \\
\text { Martin Corp., Norfolk Southern Corp., } \\
\text { Northrop Grumman Corp., RR Donnelley \& } \\
\text { Sons Co., Raytheon Co., The Sherwin- } \\
\text { Williams Co., Union Pacific Corp. }\end{array}$ & 22 \\
\hline 08/03/2010 & 9 & $\begin{array}{l}\text { Altria Group, Anadarko Petroleum Corp., } \\
\text { Devon Energy, Duke Energy Carolinas, } \\
\text { Halliburton Co., Newell Rubbermaid, Toll } \\
\text { Brothers, Valero Energy, Whirlpool Corp. }\end{array}$ & 31 \\
\hline $29 / 03 / 2010$ & 15 & $\begin{array}{l}\text { AutoZone, CBS Corp., Comcast Corp., Cox } \\
\text { Communications, Darden Restaurants, News } \\
\text { America, Nordstrom, Safeway, Southwest } \\
\text { Airlines Co., Target Corp., The Home Depot, } \\
\text { The Kroger Co., The Walt Disney Co., Time } \\
\text { Warner, Wal-Mart Stores }\end{array}$ & 46 \\
\hline $19 / 04 / 2010$ & 9 & $\begin{array}{l}\text { Alcoa, Computer Sciences Corp., E. I. du } \\
\text { Pont de Nemours and Co., Eastman } \\
\text { Chemical Co., Hewlett-Packard Co., IBM } \\
\text { Co., International Paper Co., The Dow } \\
\text { Chemical Co., Xerox Corp. }\end{array}$ & 55 \\
\hline $10 / 05 / 2010$ & 13 & $\begin{array}{l}\text { Aetna, American Express Co., Amgen, } \\
\text { Baxter International, Boeing Capital Corp., } \\
\text { Bristol-Myers Squibb Co., Capital One Bank } \\
\text { (USA), National Association, Cardinal } \\
\text { Health, CIGNA Corp., General Electric } \\
\text { Capital Corp., Marsh \& McLennan Co., } \\
\text { National Rural Utilities Cooperative Finance } \\
\text { Corp., Simon Property Group }\end{array}$ & 68 \\
\hline $07 / 06 / 2010$ & 1 & Burlington Northern Santa Fe (BNSF) & 69 \\
\hline $06 / 07 / 2010$ & 1 & CenturyLink & 70 \\
\hline 09/08/2010 & 10 & $\begin{array}{l}\text { Campbell Soup Co., Canadian Natural } \\
\text { Resources, Conagra Foods, Conocophillips, } \\
\text { Fortune Brands, General Mills, Johnson } \\
\text { Controls, Kraft Foods, Sara Lee, The Black } \\
\text { \& Decker Corp. }\end{array}$ & 80 \\
\hline $30 / 08 / 2010$ & 8 & $\begin{array}{l}\text { CVS Caremark Corp., Kohl's Corp., Lowe's } \\
\text { Companies, McDonald's Corp., McKesson } \\
\text { Corp., Omnicom Group, The TJX }\end{array}$ & 88 \\
\hline
\end{tabular}




\begin{tabular}{|c|c|c|c|}
\hline & & Companies, Viacom & \\
\hline $28 / 02 / 2011$ & 1 & Motorola Solutions & 89 \\
\hline 28/03/2011 & 10 & $\begin{array}{l}\text { Barrick Gold Corp., Carnival Corp., Cisco } \\
\text { Systems, Dell, Freeport-McMoRan Copper } \\
\text { \& Gold, MDC Holdings, Marriott } \\
\text { International, Reynolds American, Staples, } \\
\text { YUM! Brands }\end{array}$ & 99 \\
\hline $11 / 04 / 2011$ & 10 & $\begin{array}{l}\text { ACE, Boston Properties Limited Partnership, } \\
\text { ERP Operating Limited Partnership, GATX } \\
\text { Corp., Loews Corp., MetLife, The Allstate } \\
\text { Corp., The Chubb Corp., The Hartford Fin. } \\
\text { Services Group, Vornado Realty }\end{array}$ & 109 \\
\hline $02 / 05 / 2011$ & 8 & $\begin{array}{l}\text { Avnet, Kinder Morgan Energy Partners, } \\
\text { Pfizer, Quest Diagnostics, Ryder System, } \\
\text { Transocean, United Parcel Service, } \\
\text { UnitedHealth Group }\end{array}$ & 117 \\
\hline $13 / 06 / 2011$ & 10 & $\begin{array}{l}\text { American International Group, Berkshire } \\
\text { Hathaway, CA, Capital One Financial Corp., } \\
\text { DIRECTV Holdings, Expedia, Pitney } \\
\text { Bowes, SLM Corp., Time Warner Cable, } \\
\text { Tyson Foods }\end{array}$ & 127 \\
\hline $14 / 11 / 2011$ & 4 & $\begin{array}{l}\text { Boston Scientific, Heinz, Macy's, Nabors } \\
\text { Industries }\end{array}$ & 131 \\
\hline 09/10/2012 & 5 & $\begin{array}{l}\text { HCP, Lincoln National Corp., Prologis, } \\
\text { Prudential Fin., The Travelers Companies }\end{array}$ & 136 \\
\hline $22 / 10 / 2012$ & 6 & $\begin{array}{l}\text { Apache Corp., Chevron Corp., Encana Corp., } \\
\text { Energy Transfer Partners, Nexen, } \\
\text { Weatherford International }\end{array}$ & 142 \\
\hline $05 / 11 / 2012$ & 9 & $\begin{array}{l}\text { Kimco Realty Corp., Nucor Corp., Pacific } \\
\text { Gas and Electric Co., Starwood Hotels \& } \\
\text { Resorts, Textron Fin. Corp., Textron Inc., } \\
\text { The Procter \& Gamble Co., The Williams } \\
\text { Companies, VF Corp. }\end{array}$ & 151 \\
\hline $30 / 09 / 2013$ & 8 & $\begin{array}{l}\text { Avon Products, Block Financial, Caterpillar } \\
\text { Financial and Services Corp., Ford Motor } \\
\text { Co., Genworth Holdings, MeadWestvaco } \\
\text { Corp., The Boeing Co., The Gap }\end{array}$ & 159 \\
\hline
\end{tabular}

By examining reference entities with information disclosed by the DTCC-TIW on CDS outstanding notional and the number of traded contracts, we observe a gradual move towards central clearing. From 2010 onwards, the total cleared CDS notional amount increased from $\$ 82$ billion to $\$ 128$ billion in $2011, \$ 135$ billion in 2012 , and then decreased slightly to $\$ 122$ 
billion in 2013. The total notional of bilaterally traded CDS contracts decreased from $\$ 215$ billion in 2010 to $\$ 145$ billion in 2011, $\$ 105$ billion in 2012 , and $\$ 72$ billion in 2013 . The total number of traded contracts that are centrally cleared increased from about 165,000 in 2010 to 257,000 in $2011,281,000$ in 2012 , and then decreased to 248,000 in 2013 . The number of traded contracts that are bilaterally settled also decreased gradually $(434,000$ in $2010,316,000$ in $2011,283,000$ in 2012, and 203,000 in 2013).

As in Acharya and Johnson (2007), the variable used to capture independent news arriving in the CDS market that is not yet incorporated into the stock market at the time is defined as the CDS innovation. To estimate this CDS innovation, we first construct the daily CDS return as the difference in the logarithm of the CDS premium over two consecutive days. We retrieve the daily stock returns for these firms from the Center for Research in Security Prices (CRSP). For each firm $i$, we run a time-series regression of the firm's CDS return on a constant, five lags of the CDS return, the firm's contemporaneous stock return and its five lags, as well as the product of these stock returns with the firm's inverse CDS premium:

$$
\begin{aligned}
(\text { CDS Ret })_{i, t} & =a_{i}+\sum_{j=1}^{5} b_{i, j}(\text { CDS Ret })_{i, t-j} \\
& +\sum_{j=0}^{5}\left(c_{i, j}+d_{i, j} /(\text { CDS Premium })_{i, t}\right)(\text { Stock Ret })_{i, t-j}+u_{i, t} .
\end{aligned}
$$

We then define the CDS innovation $\left(C D S \operatorname{Inn} n_{i, t}\right)$ as the estimated residual $\hat{u}_{i, t}$ from the above time-series regression. CDSInn captures news specific to the CDS market and measures the magnitude of the departure of actual CDS returns from the expected returns estimated from equation (1), or the "surprise component" of CDS returns. ${ }^{6}$ We create two CDS innovation series. The first is the positive part of CDSInn $\left(C D \operatorname{SIn} n^{+}\right)$. When CDSInn is negative, this

\footnotetext{
${ }^{6}$ The dependence of the stock return coefficients on the inverse of the CDS level in equation (1) is designed to capture the nonlinear relation between the credit spread and the stock return in the classical Merton (1974) model (see Acharya and Johnson (2007), p. 120).
} 
variable is set equal to zero. The second is the negative part of CDSInn (CDSInn $\left.{ }^{-}\right)$. When CDSInn is positive, this variable is set equal to zero. Positive CDS innovation, CDSInn ${ }^{+}$, indicates an unexpected increase in the CDS premium: fresh negative information about the firm is uniquely incorporated into its CDS premium before being impounded into its stock price. $^{7}$

We report the summary statistics of the positive and negative parts of daily CDS innovations in Table 2.

\footnotetext{
${ }^{7}$ Both CDS and equity can be viewed as derivatives written on the firm value. Therefore, they are likely to be affected by the same set of market risk factors. However, given that we regress CDS returns on contemporaneous and lagged stock returns in equation (1), the CDS residuals should not be correlated with these market risk factors. For example, we calculate the correlation between each firm's CDS innovation and the change in the VIX at the daily frequency and then derive the mean (median) of the correlations across all firms in the sample. As expected, the average (median) correlation across all firms is only 0.0296 (0.0294). We also calculate the correlation between each firm's CDS innovation and the changes in the 1-year, 5 -year, and 10-year constant maturity Treasury yields at the daily frequency. The mean (median) correlations across all firms in the sample are very low: $-0.0423(-0.0325),-0.0423(-0.0419)$, and $-0.0467(-0.0474)$, respectively. These figures reinforce the notion that the CDS innovations incorporate firm-specific news, rather than common market-wide shocks.
} 


\section{Table 2 Summary statistics}

This table presents the summary statistics for all variables. $\operatorname{CDSInn}^{+}$and $\operatorname{CDSInn}^{-}$are the positive and negative parts of CDS innovation (winsorized at the top and bottom 1\%, respectively) and are expressed in percentages. CDS innovation is calculated as the residuals from the time-series regression equation (1). CDS Premium is the daily composite five-year CDS premium in basis points. CDS Return is calculated as the difference in the logarithm of the CDS premium over two consecutive days; then it is annualized by multiplying by 252. Daily Stock Return is directly retrieved from the Center for Research in Security Prices (CRSP); it is then annualized by multiplying by 252. Ln(Notional Value) is the natural logarithm of the average weekly net notional value of open CDS positions (in billions of US dollars). Ln(Contracts Outstanding) is the natural logarithm of the average weekly number of CDS contracts outstanding (in thousands). CDS Market Depth is the average daily number of quote providers for the five-year CDS contract. Ln(Assets) measures firm size and is defined as the logarithm of the firm's quarterly total assets (in millions of US dollars). Leverage is defined as long-term debt plus debt in current liabilities, divided by the sum of these two variables and the market value of equity. Stock Return Volatility is defined as the standard deviation of daily stock returns from the previous quarter. Credit Rating is the firm's $\mathrm{S} \& \mathrm{P}$ credit rating converted into a numerical scale ( $\mathrm{AAA}=1, \mathrm{AA}+=2, \ldots, \mathrm{C}=21$, and $\mathrm{D}=22$ ).

Investment Grade is a dummy variable that equals one if the reference entity has an average credit rating of BBB or better, and zero otherwise. Number of Analysts is defined as the number of analysts covering the firm's stock and it is obtained from the Institutional Brokers' Estimate System (I/B/E/S). Current Ratio is the current assets divided by current liabilities. Tangible Ratio is plant, property, and equipment divided by total assets. The sample period is from 2001 to 2013.

\begin{tabular}{lccccc}
\hline \hline & Mean & St. Dev. & $25^{\text {th }}$ & Median & $7^{\text {th }}$ \\
\hline CDSInn $^{+}(\%)$ & 0.795 & 0.307 & 0.000 & 0.000 & 0.741 \\
CDSInn $^{-}(\%)$ & -0.806 & 0.166 & -0.847 & -0.020 & 0.000 \\
CDS Premium (bps) $_{\text {Daily CDS Return (\%) }}^{195.471}$ & 450.738 & 44.486 & 89.734 & 196.544 \\
Daily Stock Return (\%) & 0.018 & 11.143 & -1.532 & 0.000 & 1.102 \\
Ln(Notional Value) & -0.001 & 7.773 & -2.513 & 0.058 & 2.654 \\
Ln(Contracts Outstanding) & 20.390 & 0.715 & 19.871 & 20.416 & 20.896 \\
CDS Market Depth & 7.348 & 0.662 & 6.927 & 7.422 & 7.830 \\
Ln(Assets) & 6.122 & 4.348 & 3.000 & 5.000 & 8.000 \\
Leverage Ratio & 9.371 & 1.315 & 8.429 & 9.251 & 10.130 \\
Stock Return Volatility & 0.506 & 1.592 & 0.308 & 0.452 & 0.609 \\
Credit Rating & 0.023 & 0.021 & 0.013 & 0.018 & 0.026 \\
Investment Grade & 8.896 & 3.083 & 7.000 & 9.000 & 10.000 \\
Number of Analysts & 0.741 & 0.438 & 0.000 & 1.000 & 1.000 \\
Current Ratio & 13.824 & 7.620 & 8.000 & 13.000 & 19.000 \\
Tangible Ratio & 1.582 & 0.941 & 0.996 & 1.362 & 1.878 \\
\hline \hline
\end{tabular}




\section{Impact of DTCC disclosure and central clearing on CDS-to-stocks information flow}

When a CDS contract does not trade frequently, its premium can be "noisy" and some portion of the estimated CDS innovation may reflect this noise rather than unique information (Gehde-Trapp et al., 2015). In other words, arbitrage forces would normally tie down CDS premiums to stock prices, but when there are few liquidity providers in the CDS market, arbitrageurs cannot step in to eliminate the mispricing and the noise component of the CDS spread could persist. If the CDS innovations were exclusively attributed to noise, illiquidity, and mispricing, then they should not be able to predict future stock returns because they do not contain any material information.

However, the past literature discussed in Section 2 argues that the CDS market is particularly efficient in anticipating bad news specific to the firm. Accordingly, we should observe that positive CDS innovations $\left(C D S I n n^{+}\right)$are able to predict stock returns when bad news arrives.

In this section, we ascertain whether positive CDS innovations do contain "unique" information, ${ }^{8}$ particularly ahead of negative events, and whether the flow of information from the CDS market to the stock market declines after the DTCC disclosure and central clearing introductions. This finding would suggest that the two post-crisis transparency reforms may have reduced informed trading in the CDS market.

Acharya and Johnson (2007) and Qiu and Yu (2012) show that the impact of past CDS innovations on stock returns is greater when firms have bad forward-looking credit conditions. Their effect on stock returns should be negative and it should become even more negative when they interact with the credit condition dummies. To this end, we create three

\footnotetext{
${ }^{8}$ We run some preliminary plausibility checks on the private information content of $C D S I n n^{+}$by looking at the correlations between $\operatorname{CDSInn}^{+}$and three measures that should also capture firm-specific private information: the idiosyncratic risk priced in stock returns and analysts' forecast dispersion and forecast error of the firm's earnings per share (using data from I/B/E/S). If $C D S I n n^{+}$contains private information, then we should expect these correlations to be significantly positive. We find that all three variables are positively correlated with $\operatorname{CDSInn}^{+}$. The Pearson, Kendall and Spearmen correlations are all statistically significant at the $1 \%$ level and their values span from $13 \%$ to $53 \%$. These results are unreported for brevity but they are available upon request.
} 
credit condition dummies based on the future behavior of the CDS premium. CrDummyA is equal to one if the firm experiences a one-day increase in the CDS premium greater than 50 basis points within the next 5,30 , or 90 days. ${ }^{9}$ CrDummy $B$ is equal to one if the firm experiences a one-day increase in the CDS premium greater than four standard deviations above the mean daily change within the next 5, 30, or 90 days (also used by Berndt and Ostrovnaya, 2014). Finally, CrDummyC is equal to one when the CDS premium remains at a level greater than 100 basis points within the next 5, 30, or 90 days.

The additional and original hypotheses we test here are that the effect of past CDS innovations on current stock returns is more concentrated on their positive parts and, more importantly, that this effect is mitigated when the CDS market becomes more transparent due to the reduction of informed trading.

\subsection{Impact of DTCC disclosure on CDS-to-stocks information flow}

We create an AfterDTCC dummy equal to one for all the days after October 31, 2008, as the DTCC began disseminating CDS transaction information on that date. Following Acharya and Johnson (2007), our regression specification uses five lags of the stock return (Stock Ret) and CDS innovation, but distinguishes between positive and negative CDS innovations (CDSInn ${ }^{+}$ and $\left.\operatorname{CDSInn}^{-}\right)$:

$$
\begin{aligned}
& \text { Stock Ret } \text { Rit }=\alpha+\sum_{\mathrm{j}=1}^{5}\left[\left(\beta_{\mathrm{j}}^{\mathrm{C}+}+\gamma_{\mathrm{j}}^{\mathrm{C}+} \operatorname{CrDummy}_{\mathrm{i}, \mathrm{t}}+\delta_{\mathrm{j}}^{\mathrm{C}+} \operatorname{AfterDTCC}_{\mathrm{i}, \mathrm{t}}\right) \times \operatorname{CDSInn}_{\mathrm{i}, \mathrm{t}-\mathrm{j}}^{+}\right]+ \\
& \sum_{j=1}^{5}\left[\left(\beta_{j}^{\mathrm{C}-}+\gamma_{\mathrm{j}}^{\mathrm{C}-} \operatorname{CrDummy}_{\mathrm{i}, \mathrm{t}}+\delta_{\mathrm{j}}^{\mathrm{C}-} \operatorname{AfterDTCC}_{\mathrm{i}, \mathrm{t}}\right) \times \operatorname{CDSInn}_{\mathrm{i}, \mathrm{t}-\mathrm{j}}^{-}\right]+\sum_{\mathrm{j}=1}^{5}\left(\left[\beta_{\mathrm{j}}^{\mathrm{E}}+\right.\right.
\end{aligned}
$$

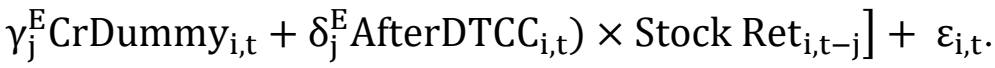

\footnotetext{
${ }^{9}$ Acharya and Johnson (2007) use a similar dummy; however, they define it to be equal to one for all days in the sample period prior to each credit event. Qiu and $\mathrm{Yu}$ (2012) suggest that when the sample period is long, it is preferable to limit the period to 5, 30, or 90 days before each credit event. In our case, the sample period can be up to 12 years long for some firms. We therefore adopt the Qiu and Yu (2012) definition.
} 
Here, $\sum_{j=1}^{5} \beta_{j}^{C+}$ represents the unconditional flow of bad news from the CDS market to the stock market, and $\sum_{j=1}^{5} \gamma_{j}^{C+}$ represents the conditional flow of bad news (i.e., given an impending credit event). Both forms of information flow have been analyzed by Acharya and Johnson (2007) and Qiu and Yu (2012), albeit not distinguishing between positive and negative CDS innovations. Based on the existing literature, we expect to find $\sum_{j=1}^{5}\left(\beta_{j}^{C+}+\right.$ $\left.\gamma_{j}^{C+}\right)<0$ with high statistical and economic significance. Meanwhile, we do not expect to see significant $\sum_{j=1}^{5} \beta_{j}^{C-}$ or $\sum_{j=1}^{5} \gamma_{j}^{C-}$ because CDS market participants are mostly focused on bad news about the firm. Finally, our additional contribution is to show whether $\sum_{j=1}^{5} \delta_{j}^{C+}>0$ : that is, the information advantage of CDS over stocks decreases (i.e., the impact of CDSInn ${ }^{+}$ becomes less negative) after the DTCC's post-trade reporting drives some informed investors away from the single-name CDS market.

We estimate equation (2) as a pooled OLS regression using daily data, with heteroskedasticity-robust standard errors clustered at the firm level, over the sample period of 2001-2013 with all CDS contracts. Each regression has nine cases, depending on which credit dummy is used (A, B, or C) and the length of the pre-credit event window (5, 30, or 90 days). We report the results for regression equation (2) in Table 3. 


\section{Table 3 Information flow from the CDS market to the stock market after DTCC starts disclosing CDS trading data (Eq. (2))}

This table presents the results of the pooled regression Eq. (2) of daily stock returns on lagged positive and negative CDS innovations (obtained from Markit CDS data using Eq. (1)) and lagged stock returns, as follows:

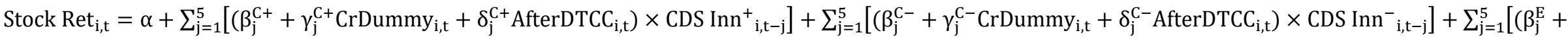
$\left.\gamma_{\mathrm{j}}^{\mathrm{E}} \mathrm{CrDummy}_{\mathrm{i}, \mathrm{t}}+\delta_{\mathrm{j}}^{\mathrm{E}} \mathrm{AfterDTCC}_{\mathrm{i}, \mathrm{t}}\right) \times$ Stock Ret $\left._{\mathrm{i}, \mathrm{t}-\mathrm{j}}\right]+\varepsilon_{\mathrm{i}, \mathrm{t}}$

where the credit condition dummies are defined in three different ways: (A) the dummy is equal to one if the firm experiences a one-day increase in the CDS premium greater than 50 basis points within the next 5,30 , or 90 days; (B) the dummy is equal to one if the firm experiences a one-day increase in the CDS premium greater than four standard deviations above the mean daily change within the next 5, 30, or 90 days; (C) the dummy is equal to one if the CDS premium of the firm remains at a level greater than 100 basis points within the next 5, 30, or 90 days. The sample includes 744 CDS contracts (both cleared and non-cleared) and it goes from 2001 to 2013 (total observations: 1,171,853). Heteroskedasticity-robust $t$-statistics adjusted for clustering within firms are in parentheses. Significance at the $10 \%, 5 \%$, and $1 \%$ levels is indicated by *,**, and $* * *$, respectively.

\begin{tabular}{|c|c|c|c|c|c|c|c|c|c|}
\hline & \multicolumn{3}{|c|}{ Specification A } & \multicolumn{3}{|c|}{ Specification B } & \multicolumn{3}{|c|}{ Specification $\mathrm{C}$} \\
\hline & 5 days & 30 days & 90 days & 5 days & 30 days & 90 days & 5 days & 30 days & 90 days \\
\hline \multirow[t]{2}{*}{$\sum \beta_{\mathrm{j}}^{\mathrm{C}+}$} & 0.001 & 0.001 & 0.000 & 0.002 & 0.002 & 0.001 & -0.006 & -0.004 & -0.004 \\
\hline & $(0.44)$ & $(0.27)$ & $(0.11)$ & $(0.58)$ & $(0.80)$ & $(0.23)$ & $(2.47)$ & $(1.76)$ & $(1.70)$ \\
\hline \multirow[t]{2}{*}{$\sum \beta_{\mathrm{j}}^{\mathrm{C}-}$} & $-0.013 * * *$ & $-0.007 * * *$ & $-0.006^{* * *}$ & $-0.013 * * *$ & $-0.016^{* * *}$ & $-0.016^{* * *}$ & -0.002 & -0.003 & -0.003 \\
\hline & $(4.38)$ & $(2.82)$ & $(2.35)$ & $(4.53)$ & $(5.45)$ & $(5.30)$ & $(1.00)$ & (1.14) & (1.09) \\
\hline \multirow[t]{2}{*}{$\sum \gamma_{\mathrm{j}}^{\mathrm{C}+}$} & $-0.112 * * *$ & $-0.070 * * *$ & $-0.041 * * *$ & $-0.122 * * *$ & $-0.065^{* * *}$ & $-0.035 * * *$ & $-0.021 * * *$ & $-0.023 * * *$ & $-0.031 * * *$ \\
\hline & $(4.35)$ & $(5.74)$ & $(3.79)$ & $(4.00)$ & $(5.83)$ & $(4.25)$ & $(3.64)$ & $(3.78)$ & $(5.57)$ \\
\hline$\sum \gamma_{\mathrm{j}}^{\mathrm{C}-}$ & 0.008 & -0.008 & 0.001 & 0.017 & $0.026 * * *$ & $0.026 * * *$ & -0.005 & -0.008 & $-0.011 * *$ \\
\hline
\end{tabular}




\begin{tabular}{|c|c|c|c|c|c|c|c|c|c|}
\hline & $(0.55)$ & $(0.91)$ & $(0.08)$ & (1.17) & $(2.80)$ & $(4.63)$ & $(1.03)$ & $(1.42)$ & $(1.97)$ \\
\hline \multirow[t]{2}{*}{$\sum \delta_{\mathrm{j}}^{\mathrm{C}+}$} & $0.081 * * *$ & $0.079 * * *$ & $0.075^{* * *}$ & $0.076^{* * *}$ & $0.079 * * *$ & $0.076^{* * *}$ & $0.082 * * *$ & $0.087 * * *$ & $0.091 * * *$ \\
\hline & $(9.28)$ & (10.42) & $(9.41)$ & $(9.03)$ & (10.29) & $(9.61)$ & (10.87) & (11.64) & (12.81) \\
\hline \multirow[t]{2}{*}{$\sum \delta_{\mathrm{j}}^{\mathrm{C}-}$} & $0.011^{*}$ & $0.011^{*}$ & 0.009 & $0.012^{*}$ & $0.012^{*}$ & 0.010 & 0.010 & $0.011^{*}$ & $0.013 * *$ \\
\hline & (1.73) & (1.79) & $(1.45)$ & $(1.78)$ & $(1.71)$ & $(1.55)$ & (1.53) & $(1.66)$ & $(2.06)$ \\
\hline \multirow[t]{2}{*}{$\Sigma \beta_{\mathrm{j}}^{\mathrm{E}}$} & $-0.079 * * *$ & $-0.084 * * *$ & $-0.084 * * *$ & $-0.074 * * *$ & $-0.060 * * *$ & $-0.047 * * *$ & $-0.091 * * *$ & $-0.091 * * *$ & $-0.093 * * *$ \\
\hline & $(8.95)$ & $(8.97)$ & $(8.46)$ & $(8.20)$ & $(6.11)$ & $(4.46)$ & (12.23) & (12.00) & (13.28) \\
\hline \multirow[t]{2}{*}{$\sum \gamma_{j}^{\mathrm{E}}$} & $0.108^{* * *}$ & $0.078 * * *$ & $0.064 * * *$ & $0.153^{* * *}$ & 0.001 & $-0.030 * *$ & $0.038 * * *$ & $0.039 * * *$ & $0.046^{* * *}$ \\
\hline & (4.34) & $(4.63)$ & $(4.11)$ & $(4.70)$ & $(0.05)$ & (2.15) & $(3.25)$ & (3.34) & $(4.12)$ \\
\hline \multirow[t]{2}{*}{$\sum \delta_{\mathrm{j}}^{\mathrm{E}}$} & $-0.027^{*}$ & $-0.025^{*}$ & $-0.025^{*}$ & -0.023 & -0.021 & -0.023 & $-0.028^{* *}$ & $-0.029 * *$ & $-0.032 * *$ \\
\hline & (1.88) & $(1.75)$ & $(1.75)$ & $(1.56)$ & $(1.48)$ & (1.63) & $(1.97)$ & $(2.01)$ & $(2.48)$ \\
\hline \multirow[t]{2}{*}{ Constant } & $<0.001^{* * *}$ & $<0.001 * * *$ & $<0.001 * * *$ & $<0.001 * * *$ & $<0.001 * * *$ & $<0.001 * * *$ & $<0.001 * * *$ & $<0.001 * * *$ & $<0.001 * * *$ \\
\hline & (7.17) & (10.58) & (11.10) & $(7.47)$ & (7.66) & $(8.32)$ & (11.82) & (11.20) & (10.65) \\
\hline Observations & $1,171,853$ & $1,171,853$ & $1,171,853$ & $1,171,853$ & $1,171,853$ & $1,171,853$ & $1,171,853$ & $1,171,853$ & $1,171,853$ \\
\hline
\end{tabular}


In all cases, we find that $\sum_{j=1}^{5}\left(\beta_{j}^{C+}+\gamma_{j}^{C+}\right)<0$ and $\sum_{j=1}^{5} \delta_{j}^{C+}>0$. In other words, past $\operatorname{CDSInn}^{+}$has a negative and significant effect on current stock returns ahead of credit events. However, this negative effect is mitigated after the disclosure of CDS transaction data.

Take Specification A with a five-day pre-credit event period, for instance. Before the DTCC disclosure date, we find that $\sum_{j=1}^{5}\left(\beta_{j}^{C+}+\gamma_{j}^{C+}\right)=-0.111$, which represents an 11.1 percent transmission of information from past positive CDS innovations to current stock returns during the five days prior to the credit event. This figure is higher than the finding of 6.5 percent documented by Qiu and Yu (2012). One possible explanation is that we are looking only at the impact of $C D S I n n^{+}$, while the impact of $\operatorname{CDSInn}^{-}$is conceivably weaker. A further explanation is that our sample period extends beyond 2008, including the whole GFC period and the subsequent recession, when more credit events have occurred for a larger number of firms. As in Qiu and Yu (2012), we consistently find that the magnitude of $\sum_{j=1}^{5}\left(\beta_{j}^{C+}+\gamma_{j}^{C+}\right)$ is higher when the pre-event window is shorter, since informed trading is more likely to occur when the credit event is getting closer.

After the DTCC disclosure date, however, we find that the information transmission from CDS to stocks is drastically curtailed. For the same case that we have just considered, we find that $\sum_{j=1}^{5}\left(\beta_{j}^{C+}+\gamma_{j}^{C+}+\delta_{j}^{C+}\right)=-0.03$, which is much smaller in size compared to before the DTCC disclosure date. This pattern holds across the board for the other specifications as well. It seems that the negative impact of $\operatorname{CDSInn}^{+}$on future stock returns is diminished or completely reversed after the DTCC data disclosure started.

As expected, we do not find significant information content in negative CDS innovations. Only $\sum_{j=1}^{5} \beta_{j}^{C-}$ has a significantly negative coefficient in Specifications $\mathrm{A}$ and $\mathrm{B}$, but it is economically less relevant (around 1\% information transmission). This is consistent with the 
literature that attributes CDS price discovery to the ability of CDSs to quickly impound firmspecific negative information.

\subsection{Impact of central clearing on CDS-to-stocks information flow}

Next, we create an AfterClearing dummy equal to one for all the days after the commencement of central clearing by ICECC for each centrally cleared CDS contract. We estimate the following pooled OLS regression at the daily frequency, with heteroskedasticityrobust standard errors clustered at the firm level, using all CDS contracts over the sample period of 2001-2013: $:^{10}$

Stock Ret ${ }_{i, \mathrm{t}}=$

$\alpha+\sum_{\mathrm{j}=1}^{5}\left[\left(\beta_{\mathrm{j}}^{\mathrm{C}+}+\gamma_{\mathrm{j}}^{\mathrm{C}+} \mathrm{CrDummy}_{\mathrm{i}, \mathrm{t}}+\delta_{\mathrm{j}}^{\mathrm{C}+}\right.\right.$ AfterClearing $\left.\left._{\mathrm{i}, \mathrm{t}}\right) \times \operatorname{CDSInn}_{\mathrm{i}, \mathrm{t}-\mathrm{j}}^{+}\right]+\sum_{\mathrm{j}=1}^{5}\left[\left(\beta_{\mathrm{j}}^{\mathrm{C}-}+\right.\right.$

$\gamma_{\mathrm{j}}^{\mathrm{C}-} \operatorname{CrDummy}_{\mathrm{i}, \mathrm{t}}+\delta_{\mathrm{j}}^{\mathrm{C}-}$ AfterClearing $\left.\left._{\mathrm{i}, \mathrm{t}}\right) \times \operatorname{CDSInn}_{\mathrm{i}, \mathrm{t}-\mathrm{j}}^{-}\right]+\sum_{\mathrm{j}=1}^{5}\left(\left[\beta_{\mathrm{j}}^{\mathrm{E}}+\gamma_{\mathrm{j}}^{\mathrm{E}} \operatorname{CrDummy}_{\mathrm{i}, \mathrm{t}}+\right.\right.$

$\delta_{\mathrm{j}}^{\mathrm{E}}$ AfterClearing $\left._{\mathrm{i}, \mathrm{t}}\right) \times$ Stock $_{\text {Ret }} \mathrm{i}, \mathrm{t}-\mathrm{j}_{\mathrm{j}}$

Our main hypothesis is $\sum_{j=1}^{5} \delta_{j}^{C+}>0$; that is, we expect the information flow from positive CDS innovations to stocks to diminish after the commencement of central clearing.

The pooled regression equation (3) has nine cases, depending on which credit dummy is used (A, B, or C) and on the length of the pre-credit event window (5, 30, or 90 days). We report the results for regression equation (3) in Table 4. For Specifications A and B, we find that $\sum_{j=1}^{5}\left(\beta_{j}^{C+}+\gamma_{j}^{C+}\right)<0$ and $\sum_{j=1}^{5} \delta_{j}^{C+}>0 .{ }^{12}$ In other words, $C D \operatorname{SInn}^{+}$has a negative and

\footnotetext{
${ }^{10}$ Note that we have also estimated the pooled regressions (3) and (4) using only the cleared CDS contracts. The results remain qualitatively similar.

${ }^{11}$ We have tried to estimate equations (1), (2), and (3) using three lags instead of five. Results are very similar.

${ }^{12}$ For Specification C, we find that $\sum_{j=1}^{5} \gamma_{j}^{C+}<0$ and $\sum_{j=1}^{5} \delta_{j}^{C+}>0$, but the estimated coefficients $\sum_{j=1}^{5} \gamma_{j}^{C+}$ are lower in absolute value. We think it is because the credit-dummy used in Specification C (CDS spread being consistently higher than $100 \mathrm{bps}$ ) does not indicate a sudden increase in CDS spreads.
} 
significant effect on future stock returns ahead of credit events. However, this negative effect is mitigated after the introduction of central clearing. 


\section{Table 4 Information flow from the CDS market to the stock market after ICECC central clearing commencement (Eq. (3))}

This table presents the results of the pooled regression Eq. (3) of daily stock returns on lagged positive and negative CDS innovations (obtained from Markit CDS data using Eq. (1)) and lagged stock returns as follows:

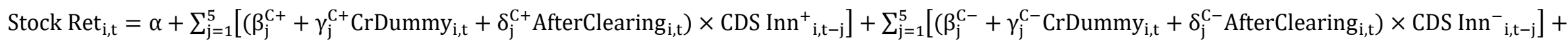
$\sum_{\mathrm{j}=1}^{5}\left[\left(\beta_{\mathrm{j}}^{\mathrm{E}}+\gamma_{\mathrm{j}}^{\mathrm{E}}\right.\right.$ CrDummy $_{\mathrm{i}, \mathrm{t}}+\delta_{\mathrm{j}}^{\mathrm{E}}$ AfterClearing $\left._{\mathrm{i}, \mathrm{t}}\right) \times$ Stock Ret $\left._{\mathrm{i}, \mathrm{t}-\mathrm{j}}\right]+\varepsilon_{\mathrm{i}, \mathrm{t}}$

where the credit condition dummies are defined in three different ways: (A) the dummy is equal to one if the firm experiences a one-day increase in the CDS premium greater than 50 basis points within the next 5, 30, or 90 days; (B) the dummy is equal to one if the firm experiences a one-day increase in the CDS premium greater than four standard deviations above the mean daily change within the next 5, 30, or 90 days; (C) the dummy is equal to one if the CDS premium of the firm remains at a level greater than 100 basis points within the next 5, 30, or 90 days. The sample includes 744 CDS contracts (both cleared and non-cleared) and it goes from 2001 to 2013 (total observations: $1,171,853)$. Heteroskedasticity-robust $t$-statistics adjusted for clustering within firms are in parentheses. Significance at the $10 \%, 5 \%$, and $1 \%$ levels is indicated by $*, * *$, and $* * *$, respectively.

\begin{tabular}{|c|c|c|c|c|c|c|c|c|c|}
\hline & \multicolumn{3}{|c|}{ Specification A } & \multicolumn{3}{|c|}{ Specification B } & \multicolumn{3}{|c|}{ Specification $\mathrm{C}$} \\
\hline & 5 days & 30 days & 90 days & 5 days & 30 days & 90 days & 5 days & 30 days & 90 days \\
\hline$\sum \beta_{\mathrm{j}}^{\mathrm{C}+}$ & (7.59) & $(7.56)$ & $(8.03)$ & $(6.98)$ & (7.01) & $(7.05)$ & $(2.44)$ & $(3.21)$ & $(3.65)$ \\
\hline \multirow[t]{2}{*}{$\sum \beta_{\mathrm{j}}^{\mathrm{C}-}$} & $-0.009 * * *$ & -0.003 & -0.003 & $-0.010 * * *$ & $-0.013 * * *$ & $-0.013 * * *$ & 0.000 & 0.001 & 0.001 \\
\hline & $(3.33)$ & $(1.52)$ & $(1.28)$ & $(3.36)$ & $(4.31)$ & $(4.25)$ & $(0.16)$ & $(0.27)$ & $(0.47)$ \\
\hline \multirow[t]{2}{*}{$\sum \gamma_{\mathrm{j}}^{\mathrm{C}+}$} & $-0.106^{* * *}$ & $-0.065 * * *$ & $-0.041 * * *$ & $-0.122 * * *$ & $-0.061 * * *$ & $-0.036 * * *$ & -0.004 & -0.008 & $-0.013 * *$ \\
\hline & $(4.66)$ & $(5.92)$ & (5.18) & $(4.34)$ & $(5.83)$ & $(5.76)$ & $(0.92)$ & $(1.62)$ & $(2.39)$ \\
\hline \multirow[t]{2}{*}{$\sum \gamma_{\mathrm{j}}^{\mathrm{C}-}$} & 0.011 & -0.007 & $<0.000$ & 0.019 & $0.028 * * *$ & $0.026^{* * *} *$ & -0.005 & -0.008 & $-0.010^{*}$ \\
\hline & $(0.75)$ & $(0.76)$ & $(0.04)$ & (1.34) & $(3.16)$ & $(4.49)$ & $(0.99)$ & $(1.42)$ & $(1.66)$ \\
\hline
\end{tabular}




\begin{tabular}{|c|c|c|c|c|c|c|c|c|c|}
\hline \multirow[t]{2}{*}{$\sum \delta_{\mathrm{j}}^{\mathrm{C}+}$} & $0.048 * * *$ & $0.048 * * *$ & $0.048 * * *$ & $0.056 * * *$ & $0.057 * * *$ & $0.055^{* * *}$ & $0.060 * * *$ & $0.059 * * *$ & $0.063 * * *$ \\
\hline & $(6.48)$ & $(6.55)$ & $(6.65)$ & $(8.10)$ & $(8.40)$ & (7.79) & $(8.14)$ & (8.29) & $(8.37)$ \\
\hline \multirow[t]{2}{*}{$\sum \delta_{\mathrm{j}}^{\mathrm{C}-}$} & $0.036 * * *$ & $0.034 * * *$ & $0.034 * * *$ & $0.038 * * *$ & $0.040 * * *$ & $0.039 * * *$ & $0.036 * * *$ & $0.038 * * *$ & $0.045 * * *$ \\
\hline & $(5.30)$ & $(4.94)$ & $(4.96)$ & $(5.64)$ & $(5.93)$ & $(5.58)$ & $(5.14)$ & $(5.50)$ & $(6.25)$ \\
\hline \multirow[t]{2}{*}{$\sum \beta_{\mathrm{j}}^{\mathrm{E}}$} & $-0.091 * * *$ & $-0.095^{* * *}$ & $-0.096^{* * *}$ & $-0.084 * * *$ & $-0.069 * * *$ & $-0.057 * * *$ & $-0.098 * * *$ & $-0.099 * * *$ & $-0.102 * * *$ \\
\hline & (10.66) & (12.18) & (11.52) & (10.08) & $(7.81)$ & $(6.14)$ & (14.56) & (14.95) & (16.38) \\
\hline \multirow[t]{2}{*}{$\sum \gamma_{\mathrm{j}}^{\mathrm{E}}$} & $0.105 * * *$ & $0.077 * * *$ & $0.064 * * *$ & $0.151 * * *$ & 0.002 & $-0.029 * *$ & $0.032 * * *$ & $0.033 * * *$ & $0.040 * * *$ \\
\hline & $(4.26)$ & $(4.63)$ & $(4.12)$ & $(4.70)$ & $(0.11)$ & $(2.08)$ & $(2.79)$ & $(2.81)$ & $(3.54)$ \\
\hline \multirow[t]{2}{*}{$\sum \delta_{\mathrm{j}}^{\mathrm{E}}$} & -0.005 & -0.002 & -0.003 & -0.016 & $-0.026^{*}$ & $-0.034 * *$ & -0.016 & -0.016 & -0.020 \\
\hline & $(0.37)$ & $(0.12)$ & $(0.19)$ & $(1.22)$ & $(1.94)$ & $(2.47)$ & $(1.32)$ & $(1.28)$ & $(1.57)$ \\
\hline \multirow[t]{2}{*}{ Constant } & $<0.001 * * *$ & $<0.001 * * *$ & $<0.001 * * *$ & $<0.001 * * *$ & $<0.001 * * *$ & $<0.001 * * *$ & $<0.001 * * *$ & $<0.001 * * *$ & $<0.001 * * *$ \\
\hline & (10.19) & (13.36) & (14.29) & (10.23) & (10.72) & (11.44) & (13.89) & (12.98) & $(11.82)$ \\
\hline Observations & $1,171,853$ & $1,171,853$ & $1,171,853$ & $1,171,853$ & $1,171,853$ & $1,171,853$ & $1,171,853$ & $1,171,853$ & $1,171,853$ \\
\hline
\end{tabular}


Take Specification A with a five-day pre-credit event period, for instance. Before the initiation date of central clearing, we find that $\sum_{j=1}^{5}\left(\beta_{j}^{C+}+\gamma_{j}^{C+}\right)=-0.085$, which represents an 8.5 percent transmission of information from positive CDS innovation to future stock returns during the five days prior to the credit event. After the introduction of central clearing, however, we find that the information transmission from CDS to stocks is drastically curtailed. For the same case that we have just considered, we find that $\sum_{j=1}^{5}\left(\beta_{j}^{C+}+\gamma_{j}^{C+}+\delta_{j}^{C+}\right)=$ -0.037 , which is smaller in size compared to before the initiation date of central clearing. This pattern holds across the board for the other specifications as well. It seems that the introduction of central clearing reduces the negative impact of $\operatorname{CDSInn}^{+}$on future stock returns.

Once again, we do not find significant information content in negative CDS innovations. $\sum_{j=1}^{5} \beta_{j}^{C-}$ has a significantly negative coefficient only in Specification $\mathrm{B}$, but it is economically less relevant (around 1\% information transmission).

In summary, the results presented here are consistent with the following: i) there is information transmission from the CDS market to the stock market ahead of credit events; ii) CDS innovations do not solely represent noise, but only positive CDS innovations incorporate firm-specific negative information that is transmitted to the stock market; iii) the negative impact of positive CDS innovations on the stock market has weakened after an increase in post-trade transparency due to the introduction of DTCC trade reporting and ICECC central clearing. 


\section{Impact of DTCC disclosure and central clearing on positive CDS innovations}

In this section, we examine the direct impact of DTCC disclosure and the introduction of central clearing on the magnitude of the positive CDS innovation $\left(\operatorname{CDSInn}^{+}\right)$, which represents our closest proxy of CDS informativeness. We start by using panel regressions and an event dummy to investigate the effect of the DTCC post-trade disclosure on CDSInn ${ }^{+}$. Next, we repeat this analysis to examine the effect of ICECC central clearing and add propensity-score matching to provide more robust results.

\subsection{Impact of DTCC disclosure on positive CDS innovations}

Our hypothesis is that the post-trade reporting to the DTCC-TIW and the disclosure of singlename CDS transaction data to the regulators and the public (started on October 31,2008) may reduce the information asymmetry in the CDS market, hence the size of the positive CDS innovations. We test this hypothesis by performing a panel regression on $\operatorname{CDSInn}^{+}$with quarterly observations, using as the main variable of interest a dummy DTCC, which is equal to one after October 31,2008 , and zero otherwise. The impact of this dummy on CDSInn ${ }^{+}$ should be negative.

We also control for a list of CDSs and reference entity characteristics that have been shown to be related to the level of liquidity and information asymmetry, such as the CDS market depth (measured by the average daily number of quote providers for each CDS contract) and the reference entity's size, leverage, credit rating, and stock return volatility, as well as the number of analysts following the firm's stock. In addition, we control for firm and time (quarterly) fixed effects. The time fixed effects exclude the quarter related to the DTCC event in order not to subsume the DTCC dummy. The control for time fixed effects is very important as they should capture the effects of the GFC (Q1-2008, Q2-2008, Q3-2008, Q12009, and Q2-2009). 
In our first regression, we perform the analysis on the whole sample of reference entities. In this way, we examine the changes in $\operatorname{CDSInn}^{+}$around October 31, 2008 for all firms, and not only those included in the DTCC public disclosure. The reason for this is that even if a reference entity is not covered by the DTCC public dataset (as it did not enter the top 1,000), the relevant CDS transaction information for this reference entity may still be reported to the DTCC and then passed on to the regulators. It is not only the public disclosure of weekly aggregate information (i.e., market transparency), but also the ability of the regulators to see trade-level information (i.e., regulatory transparency) that can reduce informed trading and CDSInn $^{+}$. Table 5 shows that the DTCC dummy has a negative and significant impact on CDSInn $^{+}$. In Column (1), we see that holding everything else constant, there is a drop in $\operatorname{CDSInn}^{+}$of $62 \mathrm{bps}$. Taking into account the average value of $\operatorname{CDSInn}^{+}$of $80 \mathrm{bps}$, this decrease is economically quite significant. When we restrict the sample to firms that are covered by the DTCC weekly public disclosure of trading information, Column (2) shows that the drop in $\operatorname{CDSInn}^{+}$appears even more dramatic (229 bps). 


\section{Table 5 Effect of DTCC post-trade disclosure on CDSInn ${ }^{+}$: Panel regressions with whole sample vs. DTCC covered sample}

This table presents the results from the panel regressions of $\operatorname{CDSInn}^{+}$on a dummy for the quarters in which DTCC has published weekly CDS trading data and on a set of control variables, using the whole sample of reference entities and the DTCC-covered sample (i.e. only those firms that are included in DTCC public disclosure), respectively. The dependent variable is the quarterly average of daily positive CDS innovations for each reference entity. The independent variable of interest is DTCC, which equals one if the date is October 31, 2008 or after; and zero otherwise. All control variables are from the previous quarter. The positive CDS innovation variable is winsorized at the upper $1 \%$ tail of the distribution to ensure that the result is not affected by a few outliers. Coefficients on all explanatory variables are multiplied by $10^{2}$. We control for quarter dummies (time fixed effects) and for firm fixed effects. Heteroskedasticity-robust $t$-statistics adjusted for clustering within firms are in parentheses. Significance at the $10 \%, 5 \%$, and $1 \%$ levels is indicated by *, **, and $* * *$, respectively.

\begin{tabular}{lc|c}
\hline & \multicolumn{2}{c}{ Positive CDS Innovations $\left(\right.$ CDSInn $\left.{ }^{+}\right)$} \\
\cline { 2 - 3 } Specification & Whole Sample & DTCC-Covered Sample \\
\cline { 2 - 3 } & $(1)$ & $(2)$ \\
\hline DTCC & $-0.616^{* * *}$ & $-2.286^{* * *}$ \\
CDS Market Depth & $(-18.08)$ & $(-49.55)$ \\
& $-0.022^{* * *}$ & $-0.021^{* * *}$ \\
Ln(Assets) & $(-9.63)$ & $(-10.09)$ \\
& 0.022 & 0.038 \\
Leverage & $(0.94)$ & $(1.60)$ \\
& -0.005 & 0.003 \\
Credit Rating & $(-0.77)$ & $(0.46)$ \\
& $-0.009^{*}$ & -0.005 \\
Stock Return Volatility & $(-1.78)$ & $(-0.94)$ \\
& $6.465^{* * *}$ & $5.709^{* * *}$ \\
Number of Analysts & $(9.99)$ & $(10.28)$ \\
& $<0.001$ & $-0.004^{* *}$ \\
Observations & $(0.05)$ & $(-2.05)$ \\
R-squared & 16,339 & 9,985 \\
Firm Fixed Effects & 0.453 & 0.536 \\
Quarter Fixed Effects & Yes & Yes \\
(except the DTCC- & Yes & Yes \\
event quarter dummy) & & \\
Clustered Standard & Yes & Yes \\
Errors & & \\
\hline \hline
\end{tabular}

Table 5 also shows that a lower CDS market depth, a higher stock return volatility, and a smaller number of analysts following the stock are associated with an increase in positive CDS innovations. CDS market depth is a measure of liquidity and the other two potentially capture information asymmetry. These findings provide some reassurance on two important points. 
First, they suggest that the higher CDS liquidity generated by the DTCC reporting is not the only reason for a decrease in positive CDS innovations. If that were the case, we should have seen a significant and negative coefficient for CDS market depth and an insignificant coefficient for the DTCC dummy. Our result is, however, consistent with Loon and Zhong (2016), who find improving liquidity in the index CDS market following the public dissemination of real-time trade reports mandated by the DFA reforms.

Second, higher stock return volatility and a smaller number of analysts following the stock are associated with an increase in $\operatorname{CDSInn}^{+}$. As these measures are widely used in the literature to capture information asymmetry (see, amongst others, Thomas, 2002; Piotroski and Roulstone, 2004; Chan and Hameed, 2006; Crawford et al., 2012), this suggests that $\operatorname{CDSInn}^{+}$is indeed a valid measure of information asymmetry.

The DTCC event occurred on a single date (October 31, 2008) for all CDS reference entities. Since this first analysis lacks the possibility of using a "control group", we now expand it by looking at the introduction of ICECC central clearing, which represents a further improvement on the baseline DTCC regulatory and market transparency. This allows us to adopt a more sophisticated methodology to study the effect of higher transparency on CDS innovations.

\subsection{Impact of central clearing on positive CDS innovations}

We now conduct an analysis of the impact of central clearing commencement on the CDS contracts that have been cleared on ICECC over the sample period of 2009 to 2013. Our thesis is that the introduction of central clearing, through a more timely post-trade disclosure of 
information, further reduces informed trading and hence the size of the positive CDS innovation relative to the post-DTCC baseline.

\subsubsection{Differences-in-differences (DID)}

Following the empirical methodology of Batta et al. (2016), we use the standard differencesin-differences (DID) estimation in a panel data setting with quarterly observations controlling for firm and (quarterly) time fixed effects. In Table 6, $\operatorname{CDSInn}^{+}$is regressed on a clearing dummy (ClearDummy), which is equal to one if reference entity $i$ is centrally cleared by ICECC by quarter $t$, and zero otherwise. For non-cleared firms, the clearing dummy is always zero since they never experience central clearing during our sample period. Moreover, central clearing was introduced at different times for different firms. Thus, both the non-cleared firms and the subset of cleared firms that did not experience clearing introduction in a given quarter serve as the "control firms" in the DID estimation. This research design should already alleviate the concern that the "treatment firms" (i.e., the cleared firms) and the "control firms" are systematically different. The coefficient of the clearing dummy constitutes a double difference (i.e., the difference of $\operatorname{CDSInn}^{+}$before and after clearing for cleared vs. non-cleared firms), and we expect this coefficient to have a negative sign.

Importantly, we restrict the sample to only those firms that had public disclosure of trading information on the DTCC website. In this setting, we test for the impact of central clearing (introduced between 2009 and 2013) as incremental to the impact of the DTCC data disclosure (introduced in October 2008). This also allows us to include additional controls for CDS liquidity (besides the number of quote providers from Markit) available from the DTCC disclosure, such as the net notional value of open CDS positions and the number of CDS contracts outstanding. 
Our estimate of the effect of central clearing could be biased if ICECC's selection of CDS contracts for clearing anticipates their level of price informativeness. However, we do not believe this to be the case. Based on the new client onboarding procedure posted by ICECC, ${ }^{13}$ a new client who wants to clear a CDS contract would first need to establish a relationship with one of the ICE CDS clearing members. A reference entity is selected for clearing when there is a large demand for trading its CDS contracts from the participating clearing members. According to Loon and Zhong (2014), ICECC considers liquidity and open interest as the key criteria in selecting CDS for central clearing. ${ }^{14}$

As in Table 5, we include a group of CDS liquidity and credit risk variables in the regressions. These variables help to control for cross-sectional differences among firms with and without central clearing. Lastly, we include firm fixed effects to control for unobserved heterogeneities at the firm level, as well as quarterly fixed effects to control for common time trends.

Table 6 shows that the clearing dummy has a negative and significant impact. After central clearing begins, the positive CDS innovation decreases by around 7 bps in both Specification (1) and Specification (2), which includes more control variables. Table 6 also shows that $\mathrm{CDSInn}^{+}$is larger among firms with higher stock return volatility and lower CDS market depth.

\footnotetext{
${ }^{13} \mathrm{https} / / / \mathrm{www}$. theice.com/publicdocs/clear_credit/ICE_Clear_Credit_Client_Clearing_Overview.pdf.

${ }^{14}$ Our later results from a probit estimation (Table 7) also confirm that CDS reference entities with higher open interest and investment-grade ratings are more likely to be chosen by ICECC for central clearing.
} 


\section{Table 6 Effect of central clearing commencement on CDSInn ${ }^{+}$: Difference-in-difference}

This table presents the results from the panel regressions of $\operatorname{CDSInn}^{+}$on a dummy for the quarters in which a CDS entity has been centrally cleared (ClearDummy) and on a set of control variables, using the whole sample of reference entities. The dependent variable is the quarterly average of daily positive CDS innovations for each reference entity. The independent variable of interest is ClearDummy, which equals one if a reference entity is centrally cleared by ICECC by quarter $\mathrm{t}$; and zero otherwise. All control variables are from the previous quarter. The positive CDS innovation is winsorized at the upper $1 \%$ tail of the distribution to ensure that the result is not affected by a few outliers. Coefficients on all explanatory variables are multiplied by $10^{2}$. Heteroskedasticityrobust $t$-statistics adjusted for clustering within firms are reported in parentheses. We control for quarter dummies (time fixed effects) and for firm fixed effects. Significance at the $10 \%, 5 \%$, and $1 \%$ levels is indicated by $* * *$, and $* * *$, respectively.

\begin{tabular}{lcc}
\hline \hline & \multicolumn{2}{c}{ Positive CDS Innovations $\left(\mathrm{CDSInn}^{+}\right)$} \\
\cline { 2 - 3 } & $(1)$ & $(2)$ \\
\hline ClearDummy & $-0.072^{* * *}$ & $-0.073^{* *}$ \\
Ln(Notional Value) & $(-2.82)$ & $(-2.55)$ \\
& -0.015 & -0.006 \\
Ln(Contracts & $(-0.37)$ & $(-0.15)$ \\
Outstanding) & $0.142^{* *}$ & -0.006 \\
& $(2.18)$ & $(-0.08)$ \\
CDS Market Depth & $-0.034^{* * *}$ & $-0.028^{* *}$ \\
& $(-3.46)$ & $(-2.38)$ \\
Ln(Assets) & & -0.021 \\
& & $(-0.31)$ \\
Leverage Ratio & & 0.002 \\
& & $(1.01)$ \\
Credit Rating & & 0.024 \\
& & $(1.52)$ \\
Stock Return Volatility & & $1.782^{* *}$ \\
& & $(2.47)$ \\
Number of Analysts & & $0.006^{*}$ \\
& & $(1.69)$ \\
\hline Observations & Yes & 4,116 \\
R-squared & Yes & 0.648 \\
Firm Fixed Effects & Yes & Yes \\
Quarter Fixed Effects & & Yes \\
Clustered Standard Error & 5,908 & \\
\hline \hline
\end{tabular}




\subsubsection{Propensity score matching}

Next, in order to explicitly address any systematic difference between cleared and non-cleared entities, we use propensity score matching (PSM) to identify "control entities". These are firms with a similar likelihood of experiencing central clearing introduction as the actual cleared firms but that have not yet been cleared in a given quarter $t$ or that have never experienced central clearing during our sample period. To find these matching firms, we first estimate a probit model that predicts the probability of a firm's CDSs to be cleared by ICECC during the next quarter, using covariates measured in the current quarter. We then perform the same panel regression in Table 6 using various matched samples.

The probit model is fitted to a sample of both cleared and non-cleared firms. Most of the independent variables we use are the same as those included in the probit model of Loon and Zhong (2014). ${ }^{15}$ They fall into four categories related to the extent of "public interest" in the CDS contract and the reference entity: liquidity, default risk, industry affiliation, and asymmetric/public information. In Specification (1), we use only the variables related to CDS liquidity: the number of quote providers for the five-year CDS contract, the net notional value of open CDS positions, and the number of outstanding CDS contracts. In Specification (2), we add credit rating and firm financial ratios to measure default risk. Investment grade is a dummy variable that equals one if the obligor has an average rating of BBB or better. The firm financial ratios included are the leverage ratio, the current ratio, and the tangibility ratio. We also include the squared leverage ratio to allow for a nonlinear effect of financial leverage on default. In Specification (3), we include additional controls: firm size, stock volatility, and

\footnotetext{
${ }^{15}$ Loon and Zhong (2014) estimate their probit model for central clearing (which happens after December 2009) using independent variables measured at the beginning of 2009. Their matching procedure is also based on propensity scores computed using the same 2009 data. In contrast, our probit model is estimated using panel data, where we predict the likelihood of central clearing in a given quarter using covariates measured during the preceding quarter. Moreover, for firms experiencing central clearing in a given quarter, our "matching firms" are identified using propensity scores computed during the previous quarter among all non-cleared firms as well as cleared firms that begin central clearing in a later quarter. Since our sample period for central clearing extends from 2009 to 2013, our matching algorithm should work better than matching based solely on 2009 measurements.
} 
the number of analysts following the firm's stock. Table 7 reports the estimates of the probit model. Consistent with Loon and Zhong (2014), the results suggest that CDS reference entities with larger open interest and higher credit ratings are more likely to be selected by ICECC for central clearing. Also, firms with a higher number of analysts are more likely to be selected for central clearing as there is more "public interest" in them.

\section{Table 7 Probability of central clearing (probit model)}

This table reports the results from a probit model that predicts the initiation of central clearing by ICECC. The probit model is estimated using panel data, where we predict the likelihood of central clearing in a given quarter using covariates measured during the preceding quarter. The dependent variable in the probit models is ClearDummy, which equals zero before the reference entity is centrally cleared, one at the quarter of centrally clearing initiation, and missing value after that (to ensure each treated firm is matched only once). Leverage Ratio $^{2}$ is the square of leverage. Industry dummies are constructed using the Markit industry classifications. All control variables are from the previous consecutive quarter (they have been defined at Table 2). $\mathrm{N}$ is the number of firms in the sample. The number of companies that have available data on CDS Market Depth and also Ln(Notional Value) for the whole sample is 297. Among those 297 observations, there are 132 centrally-cleared CDS firms and 165 non-cleared CDS firms. Numbers in parentheses are standard error adjusted for heteroskedasticity. Statistical significance at the $10 \%, 5 \%$, and $1 \%$ levels is indicated by *,**, and ***, respectively.

\begin{tabular}{lccc}
\hline \hline & \multicolumn{3}{c}{ ClearDumm $=1$ if centrally cleared, 0 otherwise } \\
\cline { 2 - 4 } & $(1)$ & $(2)$ & $(3)$ \\
\hline CDS Market Depth & 0.032 & 0.089 & 0.066 \\
& $(0.56)$ & $(1.10)$ & $(0.71)$ \\
Ln(Notional Value) & $0.705^{* * *}$ & $0.627^{* * *}$ & $0.948^{* * *}$ \\
& $(4.66)$ & $(3.00)$ & $(3.74)$ \\
Ln(Contracts Outstanding) & 0.116 & $0.686^{* * *}$ & $0.480^{*}$ \\
& $(0.70)$ & $(3.04)$ & $(1.75)$ \\
Investment Grade & & $1.866^{* * *}$ & $1.888^{* * *}$ \\
& & $(5.94)$ & $(4.81)$ \\
Leverage Ratio & & 2.206 & 2.307 \\
& & $(1.59)$ & $(1.34)$ \\
Leverage Ratio & & -1.613 & -1.989 \\
& & $(-1.31)$ & $(-1.25)$ \\
Current Ratio & -0.001 & -0.125 \\
& & $(-0.01)$ & $(-1.45)$ \\
Tangible Ratio & 0.404 & -0.0179 \\
& & $(1.15)$ & $(-0.05)$ \\
Ln(Assets) & & $-0.253^{* * *}$ \\
Stock Volatility & & $(-4.92)$ \\
Number of Analyst & & -0.752 \\
& & & $(-0.10)$ \\
& & & $0.032^{* * *}$ \\
& & & $(2.77)$
\end{tabular}




\begin{tabular}{lccc}
\hline Industry Controls & Yes & Yes & Yes \\
Quarter Fixed Effects & Yes & Yes & Yes \\
$\mathrm{N}$ & 2,106 & 1,518 & 1,262 \\
Pseudo R $^{2}$ & 0.186 & 0.370 & 0.434 \\
\hline \hline
\end{tabular}

Next, for each cleared entity, we identify the single nearest neighbor (NN1) or the two nearest neighbors (NN2) in terms of propensity scores from the group of non-cleared entities and cleared entities that begin central clearing in a later quarter. The inclusion of the latter group improves the matching performance because they are more similar to the "treated" entities. We obtain the propensity scores from the estimates of the probit model. We also select for each cleared entity the firms with less than a one-percent difference (within 1\%) and fivepercent difference (within 5\%) in terms of propensity score from the group of non-cleared entities and cleared entities that begin central clearing in a later quarter. When we find a matching firm, we include its entire time-series of observations (with replacement) in the matched sample. By design, this propensity-score matching allows us to construct a sample of non-cleared firms that have pre-clearing characteristics relevant for central clearing, similar to the cleared firms.

In Specifications (1) to (4) in Table 8, we repeat the same panel regression analysis presented in Table 6 using the PSM samples. Specifications (1) and (2) use the NN1 and NN2 samples, respectively. Specifications (3) and (4) use as matches the firms whose propensity scores are within one or five percent of that of the cleared entity. In all of these specifications except one, the clearing dummy has a negative and statistically significant coefficient, and the size of this coefficient is very similar to the one in Table 6, which is estimated using the original sample without PSM. 


\section{Table 8 Effect of central clearing commencement on CDSInn ${ }^{+}$: Propensity score matching based on the score from probit model in Table 7}

This table presents the results from the panel regressions of $\operatorname{CDSInn}^{+}$on a dummy for the quarters in which a CDS entity has been centrally cleared (ClearDummy) and on a set of control variables, using the propensityscore matched samples. The propensity scores are calculated using the probit estimates in Table 7, Specification (3). We use four different criteria for matching: NN1 (only 1 closest match), NN2 (two closest matches), Within $1 \%$ (within $1 \%$ difference in the propensity score), and Within 5\% (within 5\% difference in the propensity score). The dependent variable is the quarterly average of daily positive CDS innovations for each reference entity. The independent variable of interest is ClearDummy, which equals one if a reference entity is centrally cleared by ICECC by quarter $t$; and zero otherwise. All control variables are from the previous quarter. The positive CDS innovation variable is winsorized at the upper $1 \%$ tail of the distribution to ensure that the result is not affected by a few outliers. Coefficients on all explanatory variables are multiplied by $10^{2}$.

Heteroskedasticity-robust $t$-statistics adjusted for clustering within firms are reported in parentheses. We control for quarter dummies (time fixed effects) and firm fixed effects. Significance at the $10 \%, 5 \%$, and $1 \%$ levels is indicated by $*$, **, and $* * *$, respectively.

\begin{tabular}{lcccc}
\hline \hline & \multicolumn{4}{c}{ Positive CDS Innovations (CDSInn $\left.{ }^{+}\right)$} \\
\cline { 2 - 5 } & NN1 & NN2 & Within & Within \\
& $-0.063^{*}$ & $-0.053^{*}$ & -0.070 & $-0.071^{*}$ \\
\hline ClearDummy & $(-1.86)$ & $(-1.81)$ & $(-1.38)$ & $(-1.76)$ \\
& 0.140 & 0.103 & $0.155^{*}$ & 0.107 \\
Ln(Notional Value) & $(1.59)$ & $(1.31)$ & $(1.84)$ & $(1.32)$ \\
& -0.153 & -0.120 & 0.124 & 0.016 \\
Ln(Contracts Outstanding) & $(-1.29)$ & $(-1.10)$ & $(0.82)$ & $(0.14)$ \\
& -0.006 & -0.014 & -0.013 & 0.000 \\
CDS Market Depth & $(-0.32)$ & $(-0.71)$ & $(-0.68)$ & $(0.02)$ \\
& -0.043 & 0.024 & -0.055 & -0.076 \\
Ln(Assets) & $(-0.42)$ & $(0.25)$ & $(-0.55)$ & $(-0.76)$ \\
& $0.296^{* *}$ & $0.263^{* *}$ & 0.238 & 0.185 \\
Leverage & $(2.39)$ & $(2.01)$ & $(1.60)$ & $(1.61)$ \\
& 0.011 & 0.004 & 0.024 & 0.010 \\
Credit Rating & $(0.48)$ & $(0.14)$ & $(0.88)$ & $(0.38)$ \\
& 2.122 & $2.976^{*}$ & $2.553 * *$ & $2.492^{* *}$ \\
Stock Return Volatility & $(1.33)$ & $(1.82)$ & $(2.28)$ & $(2.13)$ \\
& 0.005 & 0.009 & 0.008 & 0.006 \\
Number of Analysts & $(0.84)$ & $(1.61)$ & $(1.31)$ & $(1.21)$ \\
& & & & \\
\hline Observations & 3,490 & 5,448 & 1,046 & 3,902 \\
R-squared & 0.665 & 0.669 & 0.671 & 0.655 \\
Firm Fixed Effects & Yes & Yes & Yes & Yes \\
Quarter Fixed Effects & Yes & Yes & Yes & Yes \\
Clustered Standard Errors & Yes & Yes & Yes & Yes \\
\hline \hline
\end{tabular}


In unreported results, we also employ a Heckman two-step model (Heckman, 1979) to control for sample selection bias. In the first stage, we calculate the inverse Mills' ratio (Lambda) from the probit model that estimates the probability for a firm to have a centrally-cleared CDS contract (we use for this purpose the model reported at Table 7, column 3). In the second stage, we include Lambda as a covariate in our panel regression along with ClearDummy (and the other controls). In this regression we use all firms, both those with cleared and with uncleared CDS contracts. We observe that the coefficients of ClearDummy remain negative and also statistically significant at the $1 \%$ level after controlling for the inverse Mills' ratio (Lambda). After central clearing begins, the positive CDS innovation decreases by around 10 bps.

\section{Robustness checks}

\subsection{Changes in CDS-stock market integration}

Two different interpretations of the results presented can still be entertained. The first is our maintained Hypothesis $\mathrm{H} 1$ - that they are consistent with a reduction of informed trading in the CDS market. Another possibility is that the weakening of the lead-lag effect from the CDS market to the stock market may indicate a more immediate transmission of information between CDS and stock markets, once there is greater transparency in the CDS market.

Therefore, to provide further support to our argument that the diminished lead-lag effect from CDSs to stocks is due to less unique information in the CDS market, in this section we examine changes in CDS-stock market integration around central clearing and trade reporting events. We check the integration level between the CDS and the stock market for each firm by computing the correlation between stock returns (daily percentage changes) and CDS returns 
(daily spread changes), and we then evaluate changes in this correlation after the start of central clearing and DTCC reporting. To provide more robustness to the correlation measure, we use three different measures of "association" between daily CDS spread changes and daily stock returns: Pearson, Spearman, and Kendall. Pearson's correlation measures the degree of linear association between daily stock returns and CDS spread changes. Spearman's and Kendall's measure how well the relationship between the two variables can be described using a monotonic function, without requiring the function to be linear. Kapadia and $\mathrm{Pu}(2012)$ also use Kendall's correlation to measure the CDS-stock market integration.

We expect all of the correlations to have a negative sign. We interpret a more negative correlation as a sign of higher cross-market integration. Using $t$-tests, we check whether there is a statistically significant increase in correlation after the introduction of ICECC central clearing and DTCC trade reporting. We compare the mean (median) correlation in a pre-event period with the mean (median) correlation during the event period.

The results of the $t$-tests for the central clearing introduction are reported in Table 9. We use the same event window as that selected by Loon and Zhong (2014) in their similar analysis of the impact of central clearing commencement (event date) on CDS counterparty risk. The event period goes from the event date to 20 days after in order to account for possible delayed reactions from traders. The pre-event period goes from 250 to 21 days before the event date. Table 9 shows no significant changes in correlations before and during the event. We also adopt binomial tests to assess whether the proportion of reference firms which experience any increase in correlations (negative "differences") differs significantly from a random 50\% proportion. The results suggest that about $50 \%$ of the sample firms experience an increase in CDS-stock market integration, and as expected, the test never rejects the null hypothesis that it is just a random $50 \%$ proportion. We also use an alternative event period [0, 30 days] and pre-event period [ -250 days, -31 days], finding similar results. 
Table 9 Changes in CDS-stock market integration before and after the start of central clearing: $t$-tests

The table reports an analysis of changes in CDS-market integration around central clearing commencement by comparing Pearson's, Spearman's, and Kendall's correlations between daily stock returns and CDS premium changes in the 'Pre-event' period and 'Event' period. Following Loon and Zhong (2014), we use as event-period $[0,20]$ to account for possible delayed impact of central clearing. The pre-event period goes instead from day -250 to -21 days from the event. For each reference entity, 'Pre-event' ('Event') is the average or median CDSstock correlation in the pre-event (event) period. For each reference entity 'Difference' is calculated as Event minus Pre-event. Cross-sectional mean (median) of 'Pre-event', 'Event', and 'Difference' are reported. Note that the cross-sectional mean (median) difference does not come equal to the cross-sectional mean (median) 'Event' minus the mean (median) 'Pre-event' due to the unbalanced nature of our panel dataset and the presence of some missing data in the pre-event and event periods. $t$-Tests verify whether the cross-sectional mean (median) of 'Difference' is not significantly different from zero. PctNeg is the percentage of firms with negative 'difference' in CDS-stock correlations and $\mathrm{P}(\mathrm{PctNeg}=50 \%)$ is the p-value under the null that PctNeg is a random $50 \%$. Significance at the $10 \%, 5 \%$, and $1 \%$ levels is indicated by $* * *$, and $* * *$, respectively.

\begin{tabular}{cccc}
\hline \hline \multicolumn{3}{c}{ Change in Correlations between CDS premium changes and Stock returns } \\
& Pre-Clearing [-250,-21] & Pre-Clearing [-250,-21] & Pre-Clearing [-250,-21] \\
& vs. Clearing Event [0, 20] & vs. Clearing Event [0, 20] & vs. Clearing Event [0, 20] \\
& Pearson & Spearman & Kendall \\
\hline Cross-sectional Mean: & & & \\
Pre-event & -0.238 & -0.225 & -0.155 \\
Event & -0.248 & -0.231 & -0.165 \\
Difference & -0.013 & -0.016 & -0.005 \\
\hline Cross-sectional Median: & & & -0.155 \\
Pre-event & -0.263 & -0.231 & -0.200 \\
Event & -0.238 & -0.257 & -0.009 \\
Difference & 0.036 & -0.005 & \\
\hline Binomial Test: & & & $48.15 \%$ \\
PctNeg (percent) & $46.67 \%$ & $51.11 \%$ & 0.7308 \\
P(PctNeg =50\%) & 0.4913 & 0.8634 & \\
\hline \hline
\end{tabular}

The results of the $t$-tests around the DTCC trade reporting event of October 31, 2008 are illustrated in Table 10. 


\section{Table 10 Changes in CDS-stock market integration before and after the start of DTCC trade reporting: $t$-tests}

The table reports an analysis of changes in CDS-market integration around DTCC trade reporting commencement by comparing Pearson's, Spearman's, and Kendall's correlations between daily stock returns and CDS premium changes in the 'Pre-event' period and 'Event' period. Following Loon and Zhong (2014), we use as event-period $[0,20]$ to account for possible delayed impact of trade reporting. The pre-event period goes from day -250 to -21 days from the event ( 31 October 2008). For each reference entity, 'Pre-event' ('Event') is the average or median CDS-stock correlation in the pre-event (event) period. For each reference entity 'Difference' is calculated as Event minus Pre-event. Cross-sectional mean (median) of 'Pre-event', 'Event', and 'Difference' are reported. Note that the cross-sectional mean (median) difference does not come equal to the cross-sectional mean (median) 'Event' minus the mean (median) 'Pre-event' due to the unbalanced nature of our panel dataset and the presence of some missing data in the pre-event and event periods. $t$-Tests verify whether the cross-sectional mean (median) of 'Difference' is significantly different from zero. PctNeg is the percentage of firms with negative 'difference' in CDS-stock correlations and $\mathrm{P}(\mathrm{PctNeg}=50 \%)$ is the p-value under the null that PctNeg is a random 50\%. Significance at the $10 \%, 5 \%$, and $1 \%$ levels is indicated by *, **, and ***, respectively.

\begin{tabular}{|c|c|c|c|}
\hline \multicolumn{4}{|c|}{ Change in Correlations between CDS premium changes and Stock returns } \\
\hline & Pre-DTCC $[-250,-21]$ & Pre-DTCC $[-250,-21]$ & Pre-DTCC $[-250,-21]$ \\
\hline & vs. DTCC $[0,20]$ & vs. DTCC $[0,20]$ & vs. DTCC $[0,20]$ \\
\hline & Pearson & Spearman & Kendall \\
\hline \multicolumn{4}{|c|}{ Cross-sectional Mean: } \\
\hline Pre-event & -0.176 & -0.158 & -0.110 \\
\hline Event & -0.241 & -0.217 & -0.160 \\
\hline Difference & $-0.046 * * *$ & $-0.042 * * *$ & $-0.039 * * *$ \\
\hline \multicolumn{4}{|c|}{ Cross-sectional Median: } \\
\hline Pre-event & -0.178 & -0.156 & -0.107 \\
\hline Event & -0.289 & -0.253 & -0.187 \\
\hline Difference & $-0.063 * * *$ & $-0.065 * * *$ & $-0.060 * * *$ \\
\hline \multicolumn{4}{|l|}{ Binomial Test: } \\
\hline PctNeg (percent) & $58.58 \%$ & $60.94 \%$ & $60.04 \%$ \\
\hline $\mathrm{P}(\operatorname{PctNeg}=50 \%)$ & $<0.0001$ & $<0.0001$ & $<0.0001$ \\
\hline
\end{tabular}

Here, we observe a small but statistically significant increase in mean (median) CDS-stock market integration (that is, negative "differences"). However, this result requires a cautious 
interpretation due to the particular period we are looking at (October and November 2008). The peak of the GFC effects could result in higher correlation across the markets due to more systematic risk, ${ }^{16}$ rather than better information transmission. Since higher information transmission and better market integration depend on informed arbitrageurs' trading ability, we rely on one of the results of Kapadia and $\mathrm{Pu}$ (2012) - namely, that firm-specific characteristics, in particular CDS liquidity, play a key role in determining informed arbitrageurs' ability to arbitrage across stocks and CDSs. If the higher CDS-stock correlation over the DTCC reporting commencement period is due to higher information transmission, then we should also observe an improvement in CDS liquidity around that event: when there are more liquidity providers in the CDS market, arbitrageurs can step in to eliminate the mispricing, so that the CDS and stock markets align. If the higher correlation is due to more systematic risk, then we should observe instead a decline in CDS liquidity. Therefore, we repeat the $t$-tests using now CDS liquidity (measured by the number of CDS quote contributors) instead of CDS-stock market integration. Table 11 shows that there is a significant decrease in CDS liquidity around the DTCC event period.

\footnotetext{
${ }^{16}$ Kapadia and $\mathrm{Pu}$ (2012) show that a higher level of firms' idiosyncratic risk is associated to lower CDS-equity market correlation. Consistently, an increase in systematic risk can be also associated to higher CDS-equity market correlation.
} 


\section{Table 11 Changes in CDS liquidity before and after the start of DTCC trade reporting: $t$-tests}

The table reports an analysis of changes in CDS liquidity (measured by the number of quote contributors) around DTCC trade reporting commencement by comparing this variable in the 'Pre-event' period and 'Event' period. Following Loon and Zhong (2014), we use as event-period [0, 20] to account for possible delayed impact of trade reporting. The pre-event period goes from day -250 to -21 days from the event (31 October 2008). For each reference entity, 'Pre-event' ('Event') is the average or median CDS liquidity in the pre-event (event) period. For each reference entity 'Difference' is calculated as Event minus Pre-event. Cross-sectional mean (median) of 'Pre-event', 'Event', and 'Difference' are reported. Note that the cross-sectional mean (median) difference does not come equal to the cross-sectional mean (median) 'Pre-event' minus the mean (median) 'Event' due to the unbalanced nature of our panel dataset and the presence of some missing data in the pre-event and event periods. $t$-Tests verify whether the cross-sectional mean (median) of 'Difference' is significantly different from zero. PctNeg is the percentage of firms with negative 'difference' in CDS liquidity and $\mathrm{P}(\mathrm{PctNeg}=50 \%)$ is the p-value under the null that PctNeg is a random 50\%. Significance at the 10\%, 5\%, and $1 \%$ levels is indicated by $* * *$, and $* * *$, respectively.

CDS Liquidity (Number of CDS-quote contributors for firms with trade data in DTCC)

Pre-DTCC $[-250,-21]$ vs. DTCC $[0,20]$

\begin{tabular}{cc}
\hline Cross-sectional Mean: & \\
Pre-event & 10.399 \\
Event & 8.023 \\
Difference & $-2.38^{* * *}$
\end{tabular}

Cross-sectional Median:

Pre-event

11.000

Event

8.400

Difference

$-2.362 * * *$

$\begin{array}{ll}\text { Binomial Test: } & \\ \text { PctNeg (percent) } & 95.67 \% \\ \text { P(PctNeg }=50 \%) & <0.0001\end{array}$

In addition, Kapadia and $\mathrm{Pu}$ (2012) find that firms with higher leverage levels and equity volatility display more CDS-equity integration: this is consistent with the Merton's model predicting that when a firm's credit risk is higher there is a higher correlation between its stock returns and CDS spread changes. We therefore examine whether after the DTCC event there is a higher level of firms' credit risk. To do so, we repeat the $t$-tests and analyze changes 
in the firms' CDS premiums. Table 12 presents the result of the $t$-tests and confirms that CDS premiums increase significantly after the DTCC event. Taken together, these results suggest that the increase in CDS-stock market integration after the DTCC event is due to higher systematic risk rather than better information transmission between the two markets.

\section{Table 12 Changes in CDS premiums before and after the start of DTCC trade reporting: $t$-tests}

The table reports an analysis of changes in CDS premiums around DTCC trade reporting commencement by comparing this variable in the 'Pre-event' period and 'Event' period. Following Loon and Zhong (2014), we use as event-period $[0,20]$ to account for possible delayed impact of trade reporting. The pre-event period goes from day -250 to -21 days from the event (31 October 2008). For each reference entity, 'Pre-event' ('Event') is the average or median CDS premium in the pre-event (event) period. For each reference entity 'Difference' is calculated as Event minus Pre-event. Cross-sectional mean (median) of 'Pre-event', 'Event', and 'Difference' are reported. Note that the cross-sectional mean (median) difference does not come equal to the cross-sectional mean (median) 'Pre-event' minus the mean (median) 'Event' due to the unbalanced nature of our panel dataset and the presence of some missing data in the pre-event and event periods. $t$-Tests verify whether the crosssectional mean (median) of 'Difference' is significantly different from zero. PctPos is the percentage of firms with positive 'difference' in CDS premium and $\mathrm{P}(\mathrm{PctPos}=50 \%)$ is the $\mathrm{p}$-value under the null that $\mathrm{PctPos}$ is a random $50 \%$. Significance at the $10 \%, 5 \%$, and $1 \%$ levels is indicated by *,**, and ***, respectively.

CDS premium for firms with trade data in DTCC

Pre-DTCC $[-250,-21]$ vs. DTCC $[0,20]$

\section{Cross-sectional Mean:}

Pre-event

Event

Difference

$299.544 * * *$

\section{Cross-sectional Median:}

Pre-event

Event

Difference

$99.884 * * *$

\section{Binomial Test:}

PctPos (percent) 


\subsection{Concurrent changes in the CDS market}

In 2009, the CDS market witnessed a few more changes in addition to the introduction of voluntary central clearing for some reference entities. For example, in the same year, the CDS market in North America moved towards a standardization of contracts (the so-called Big Bang) in order to simplify the market and prepare it for central clearing.

Since these changes are in part concurrent with the clearing events studied in Section 5, we repeat the analysis in that section using a "placebo test": we randomly move the AfterClearing event dummies forward and backward by one or two quarters.

In Tables 13 and 14, we see that all of the placebo tests fail: the placebo-event dummy has an opposite (positive) sign in Table 13 and it is generally insignificant in both Tables 13 and 14. 


\section{Table 13 Effect of placebo-event dummy on CDSInn ${ }^{+}$: Dummy two-quarters backward and forward the 'Clearing' event}

This table presents the results from the panel regressions of $\operatorname{CDSInn}^{+}$on a placebo event-dummy for two quarters before and after the one when a CDS entity has been centrally cleared (Placebo-Dummy) and on a set of control variables, using the whole sample of reference entities. The dependent variable is the quarterly average of daily positive CDS innovations for each reference entity. The independent variable of interest is PlaceboDummy, which equals one if a reference entity is centrally cleared by ICECC by: quarter $t+2$ (columns 1 and 2) or quarter $\mathrm{t}-2$ (columns 3 and 4 ); and zero otherwise. All control variables are from the previous quarter $\mathrm{t}-1$. The positive CDS innovation is winsorized at the upper $1 \%$ tail of the distribution to ensure that the result is not affected by a few outliers. Coefficients on all explanatory variables are multiplied by $10^{2}$. Heteroskedasticityrobust $t$-statistics adjusted for clustering within firms are reported in parentheses. We control for quarter dummies (time fixed effects) and for firm fixed effects. Significance at the $10 \%, 5 \%$, and $1 \%$ levels is indicated by $*$,**, and $* * *$, respectively.

\begin{tabular}{|c|c|c|c|c|}
\hline & \multicolumn{4}{|c|}{ Positive CDS Innovations $\left(\right.$ CDSInn $\left.^{+}\right)$} \\
\hline & $\begin{array}{c}\text { (1) } \\
\text { Clearing at } \mathrm{t}+2\end{array}$ & $\begin{array}{c}(2) \\
\text { Clearing at } t+2\end{array}$ & $\begin{array}{c}(3) \\
\text { Clearing at } t-2\end{array}$ & $\begin{array}{c}\text { (4) } \\
\text { Clearing at } \mathrm{t}-2\end{array}$ \\
\hline Placebo-Dummy & $0.053 * *$ & $\begin{array}{l}0.019 \\
(065)\end{array}$ & $\begin{array}{l}0.029 \\
(114)\end{array}$ & 0.052 \\
\hline Ln(Notional & -0.009 & 0.001 & -0.011 & -0.008 \\
\hline & $(-0.24)$ & $(0.01)$ & $(-0.31)$ & $(-0.19)$ \\
\hline Ln(Contracts & $0.138 * *$ & -0.001 & $0.131^{* *}$ & 0.009 \\
\hline & $(2.21)$ & $(-0.02)$ & $(2.22)$ & $(0.14)$ \\
\hline CDS Market & $-0.030 * * *$ & $-0.023 * *$ & $-0.036 * * *$ & $-0.027 * *$ \\
\hline & $(-3.12)$ & $(-1.98)$ & $(-3.61)$ & $(-2.28)$ \\
\hline Ln(Assets) & & $\begin{array}{l}-0.022 \\
(-0.34)\end{array}$ & & $\begin{array}{l}-0.021 \\
(-0.34)\end{array}$ \\
\hline Leverage & & $\begin{array}{l}0.002 \\
(1.00)\end{array}$ & & $\begin{array}{l}0.002 \\
(1.12)\end{array}$ \\
\hline Credit Rating & & $\begin{array}{l}0.025 \\
(1.57)\end{array}$ & & $\begin{array}{l}0.023 \\
(1.58)\end{array}$ \\
\hline $\begin{array}{l}\text { Stock Return } \\
\text { Volatility }\end{array}$ & & $1.687^{* *}$ & & $1.877 * * *$ \\
\hline & & $(2.27)$ & & $(2.69)$ \\
\hline Number of & & 0.005 & & 0.005 \\
\hline & & $(1.55)$ & & $(1.63)$ \\
\hline Observations & 5,908 & 4,116 & 5,908 & 4,116 \\
\hline R-squared & 0.563 & 0.642 & 0.562 & 0.643 \\
\hline $\begin{array}{l}\text { Firm Fixed } \\
\text { Effects }\end{array}$ & Yes & Yes & Yes & Yes \\
\hline $\begin{array}{l}\text { Quarter Fixed } \\
\text { Effects }\end{array}$ & Yes & Yes & Yes & Yes \\
\hline $\begin{array}{l}\text { Clustered } \\
\text { Standard Errors }\end{array}$ & Yes & Yes & Yes & Yes \\
\hline
\end{tabular}




\section{Table 14 Effect of placebo-event dummy on CDSInn ${ }^{+}$: Dummy one-quarter backward and forward the 'Clearing' event.}

This table presents the results from the panel regressions of $\operatorname{CDSInn}^{+}$on a placebo event-dummy for one quarter before and after the one when a CDS entity has been centrally cleared (Placebo-Dummy) and on a set of control variables, using the whole sample of reference entities. The dependent variable is the quarterly average of daily positive CDS innovations for each reference entity. The independent variable of interest is Placebo-Dummy, which equals one if a reference entity is centrally cleared by ICECC by: quarter $t+1$ (columns 1 and 2) or quarter $\mathrm{t}^{-1}$ (columns 3 and 4 ); and zero otherwise. All control variables are from the previous quarter $\mathrm{t}-1$. The positive CDS innovation is winsorized at the upper $1 \%$ tail of the distribution to ensure that the result is not affected by a few outliers. Coefficients on all explanatory variables are multiplied by $10^{2}$. Heteroskedasticity-robust tstatistics adjusted for clustering within firms are reported in parentheses. We control for quarter dummies (time fixed effects) and for firm fixed effects. Significance at the $10 \%, 5 \%$, and $1 \%$ levels is indicated by *, **, and $* * *$, respectively.

\begin{tabular}{|c|c|c|c|c|}
\hline & \multicolumn{4}{|c|}{ Positive CDS Innovations $\left(\mathrm{CDSInn}^{+}\right)$} \\
\hline & $(1)$ & $(2)$ & $(3)$ & (4) \\
\hline & Clearing at $\mathrm{t}-1$ & Clearing at $\mathrm{t}-1$ & Clearing at $t+1$ & Clearing at $t+1$ \\
\hline \multirow[t]{2}{*}{ Placebo-Dummy } & -0.010 & -0.035 & $-0.044^{*}$ & -0.051 \\
\hline & $(-0.35)$ & $(-1.00)$ & $(-1.67)$ & $(-1.63)$ \\
\hline \multirow{2}{*}{$\begin{array}{l}\text { Ln(Notional } \\
\text { Value) }\end{array}$} & -0.011 & 0.000 & -0.015 & -0.009 \\
\hline & $(-0.29)$ & $(0.00)$ & $(-0.40)$ & $(-0.22)$ \\
\hline \multirow{2}{*}{$\begin{array}{l}\text { Ln(Contracts } \\
\text { Outstanding) }\end{array}$} & $0.138^{* *}$ & -0.006 & $0.140^{* *}$ & 0.020 \\
\hline & $(2.16)$ & $(-0.09)$ & $(2.30)$ & $(0.31)$ \\
\hline \multirow{2}{*}{$\begin{array}{l}\text { CDS Market } \\
\text { Depth }\end{array}$} & $-0.031 * * *$ & $-0.025 * *$ & $-0.036 * * *$ & $-0.029 * *$ \\
\hline & $(-3.20)$ & $(-2.15)$ & $(-3.63)$ & $(-2.42)$ \\
\hline \multirow[t]{2}{*}{ Ln(Assets) } & & -0.021 & & -0.035 \\
\hline & & $(-0.31)$ & & $(-0.55)$ \\
\hline \multirow[t]{2}{*}{ Leverage } & & 0.002 & & 0.002 \\
\hline & & $(0.90)$ & & $(1.09)$ \\
\hline \multirow[t]{2}{*}{ Credit Rating } & & 0.024 & & 0.022 \\
\hline & & $(1.55)$ & & $(1.46)$ \\
\hline \multirow{2}{*}{$\begin{array}{l}\text { Stock Return } \\
\text { Volatility }\end{array}$} & & $1.703 * *$ & & $1.823 * *$ \\
\hline & & $(2.31)$ & & $(2.56)$ \\
\hline \multirow{2}{*}{$\begin{array}{l}\text { Number of } \\
\text { Analysts }\end{array}$} & & 0.005 & & $0.006^{*}$ \\
\hline & & $(1.56)$ & & $(1.80)$ \\
\hline Observations & 5,908 & 4,116 & 5,908 & 4,116 \\
\hline R-squared & 0.564 & 0.645 & 0.564 & 0.647 \\
\hline $\begin{array}{l}\text { Firm Fixed } \\
\text { Effects }\end{array}$ & Yes & Yes & Yes & Yes \\
\hline $\begin{array}{l}\text { Quarter Fixed } \\
\text { Effects }\end{array}$ & Yes & Yes & Yes & Yes \\
\hline $\begin{array}{l}\text { Clustered } \\
\text { Standard Errors }\end{array}$ & Yes & Yes & Yes & Yes \\
\hline
\end{tabular}




\section{Conclusions}

In the aftermath of the GFC, there were significant changes in the single-name CDS market structure. Voluntary CDS post-trade reporting started and a major data repository, the DTCCTIW, began its public disclosure of weekly trading data on single-name CDSs. Later on, more CDS transactions moved towards central clearing on ICECC, which also began disclosing CDS positions data on a daily basis. At the same time, regulators gained more or less unfettered access to the trade-level data captured by these data repositories.

In this paper, we examine whether the higher post-trade transparency after the GFC had any impact on the CDS price informativeness and the incremental price discovery function of the CDS market relative to the stock market. The analysis of information flows from CDS to stocks demonstrates that the positive CDS innovations do not just reflect "noise", but information that is transmitted to the stock market ahead of credit events. However, the ability of these positive CDS innovations to predict future stock returns has weakened after the transparency reforms. The panel regression analysis, difference-in-differences (DID), and propensity score matching methods reveal a decrease in the positive CDS innovation, our proxy for information asymmetry, after the introduction of the DTCC disclosure and ICECC central clearing.

Taken together, our results suggest that the single-name CDS market has become much less of a "hidden" trading venue for informed investors after the GFC. On the one hand, the increase in CDS market transparency may help assuage the problem of insider trading discussed by Acharya and Johnson (2007): in this case, the changes advocated by the DFA Title VII legislation, even before they are made compulsory by SEC regulation, go towards the desired direction of reducing market abuses. On the other hand, the higher transparency may deter traders from acquiring information and dissuade informed market participants from trading. 
The loss of informed trading can hinder the price discovery role of the CDS market: this finding should be a concern for regulators who are advocating for even more transparency in the CDS market. 


\section{References}

Acharya, V. V., and Johnson, T. C. "Insider Trading in Credit Derivatives." Journal of Financial Economics, 84 (2007), 110-141.

Alloway, T. “'Swaptions' Trade Leaps over Regulatory Hurdles.” Financial Times, 31 March (2014), <https://next.ft.com/content/b79591ac-b8d6-11e3-835e-00144feabdc0>, accessed 24 January 2019.

Bai, X., Hu, N., Liu, L., and Zhu, L. "Credit Derivatives and Stock Return Synchronicity." Journal of Financial Stability, 28 (2017), 79-90.

Batta, G. E., Qiu, J., and Yu, F. "Credit Derivatives and Analyst Behavior." Accounting Review, 91 (2016), 1315-1343.

Berndt, A., and Ostrovnaya, A. "Do Equity Markets Favor Credit Market News over Options Market News?" Quarterly Journal of Finance, 4 (2014), 1-51.

Bessembinder, H., Maxwell, W., and Venkataraman, K. "Market Transparency, Liquidity Externalities, and Institutional Trading Costs in Corporate Bonds." Journal of Financial Economics, 82 (2006), 251-288.

Chan, K., and Hameed, A. "Stock Price Synchronicity and Analyst Coverage in Emerging Markets." Journal of Financial Economics 80 (2006), 115-147.

Crawford, S. S., Roulstone, D. T., and So, E. C. “Analyst Initiations of Coverage and Stock Return Synchronicity.” Accounting Review, 87 (2012), 1527-1553.

Devasabai, K. "LCH to clear single-name CDSs for US clients." Risk.net (2017), 〈https://www.risk.net/derivatives/2480399/lch-to-clear-single-name-cdss-for-us-clients>, accessed 24 January 2019. 
Edwards, A. K., Harris, L. E., and Piwowar, M. S. "Corporate Bond Market Transaction Costs and Transparency.” Journal of Finance, 62 (2007), 1421-1451.

Gehde-Trapp, M., Gündüz, Y., and Nasev, J. "The Liquidity Premium in CDS Transaction Prices: Do Frictions Matter?” Journal of Banking and Finance, 61 (2015), 184-205.

Goldstein, M. A., Hotchkiss, E. S., and Sirri, E. R. "Transparency and Liquidity: A Controlled Experiment on Corporate Bonds." Review of Financial Studies, 20 (2007), 235-273.

Grossman, S. J., and Stiglitz, J. E. "On the Impossibility of Informationally Efficient Markets.” American Economic Review, 70 (1980), 393-408.

Heckman, J. J. "Sample Selection Bias as a Specification Error.” Econometrica 47 (1979), pp. $153-161$.

Kapadia, N., and $\mathrm{Pu}, \mathrm{X}$. "Limited Arbitrage between Equity and Credit Markets." Journal of Financial Economics, 105 (2012), 542-564.

Kryzanowski, L., Perrakis, S., and Zhong, R. "Price Discovery in Equity and CDS Markets." Journal of Financial Markets, 35 (2017), 21-46.

Lee, J., Naranjo, A., and Sirmans, S. "CDS momentum: Slow Moving Credit Ratings and Cross-Market Spillovers.” Working Paper (2014).

Lee, J., Naranjo, A., and Velioglu, G. "When do CDS Spreads Lead? Rating Events, Private Entities, and Firm-specific Information Flows.” Journal of Financial Economics, 130 (2018), $556-578$.

Loon, Y. C., and Zhong, K. Z. "The Impact of Central Clearing on Counterparty Risk, Liquidity, and Trading: Evidence from the Credit Default Swap Market.” Journal of Financial Economics, 112 (2014), 91-115. 
Loon, Y. C., and Zhong, K. Z. "Does Dodd-Frank Affect OTC Transaction Costs and Liquidity? Evidence from Real-Time CDS Trade Reports.” Journal of Financial Economics, 119 (2016), 645-672.

Marra, M. "Explaining Co-movements between Equity and CDS Bid-Ask Spreads.” Review of Quantitative Finance and Accounting, 49 (2017), 811-853.

Marsh, I. W., and Wagner, W. "News-Specific Price Discovery in Credit Default Swap Markets.” Financial Management, 45 (2015), 315-340.

Merton, R. C. "On the Pricing of Corporate Debt: the Risk Structure of Interest Rates." Journal of Finance, 29 (1974), 449-470.

Naik, N. Y., Neuberger, A., and Viswanathan, S. "Trade Disclosure Regulation in Markets with Negotiated Trades.” Review of Financial Studies, 12 (1999), 873-900.

Ni, S. and Pan, J. "Trading Puts and CDS on Stocks with Short Sale Ban." Working Paper (2011).

Norden, L. "Information in CDS Spreads." Journal of Banking and Finance, 75 (2017), 118135.

Norden, L. and Weber, M. "Informational Efficiency of Credit Default Swap and Stock Markets: The Impact of Credit Rating Announcements.” Journal of Banking and Finance, 28 (2004), 2813-2843.

Norman, P. The Risk Controllers - Central Counterparty Clearing in Globalized Financial Markets, Wiley (2011).

Pagano, M., and Röell, A. "Transparency and Liquidity: A Comparison of Auction and Dealer Markets with Informed Trading.” Journal of Finance, 51 (1996), 579-611. 
Pereira da Silva, P., Vieira, C., and Vieira, I. "Central Clearing and CDS Market Quality." Journal of Future Markets, 38 (2018), 731-753.

Piotroski, J. D., and Roulstone, B. T. "The Influence of Analysts, Institutional Investors, and Insiders on the Incorporation of Market, Industry, and Firm-specific Information into Stock Prices.” Accounting Review 79 (2004), 1119-1151.

Qiu, J., and Yu, F. "Endogenous Liquidity in Credit Derivatives." Journal of Financial Economics, 103 (2012), 611-631.

Thomas, S. "Firm Diversification and Asymmetric Information: Evidence from Analysts' Forecasts and Earnings Announcements.” Journal of Financial Economics 64 (2002), 373396.

Zhang, G., and Zhang, S. "Information Efficiency of the US Credit Default Swap Market: Evidence from Earnings Surprises.” Journal of Financial Stability, 9 (2013), 720-730. 


\section{Appendix A: Post-trade transparency reforms in the US single-name CDS market}

All rules under Title VII of the 2010 Dodd-Frank Act (DFA) for security-based swaps (including single-name credit default swaps (CDSs) are not yet fully implemented almost a decade after the global financial crisis (GFC). Only in February 2015 did the Securities and Exchange Commission (SEC) produce two final rules (SEC 34-74244 and SEC 34-74245) on the public dissemination of information on single-name CDSs, but these rules are not yet obligatory. Also, central clearing is not yet mandatory in the US for single-name CDSs under the SEC rules.

Despite the sluggishness of the SEC in making Title VII of the DFA mandatory for singlename CDSs, a voluntary practice of central clearing and trade reporting has already spread and developed. Intercontinental Exchange Clear Credit (ICECC) has been active since 2009 as a clearinghouse for US single-name CDSs. Moreover, there are already four swap data repositories (SDRs) operating in the US: the Depository Trust and Clearing Corporation (DTCC), Bloomberg, ICE Trade Vault, and the CME Group. Currently, the DTCC Trade Information Warehouse (DTCC-TIW) and ICECC also provide public information on singlename CDS trades. Thus, while a complete and mandatory transparency regime of single-name CDS transactions in the US has not yet been implemented, a certain degree of transparency in the market has already been achieved.

\section{A.1. The Depository Trust and Clearing Corporation Trade Information Warehouse}

In a letter to the Federal Reserve Bank of New York, dated October 31, 2008, the 16 major CDS dealers and industry associations committed to utilizing the DTCC-TIW as a "single, centralized source of industry portfolio statistics to enhance the transparency of the market for 
participants and supervisors." ${ }^{, 17}$ Virtually all dealers and buy-side participants, along with 15 third-party service providers, are already linked to the TIW and utilize its functionality. Thus, the vast majority of traded CDS contracts are reported to it. In addition, all of the major CDS dealers have registered in the TIW many of the contracts they executed before October 31 , 2008. This makes the DTCC-TIW the single dominant provider of record-keeping services for single-name CDSs in the US.

Each recorded transaction in the DTCC-TIW contains the following information: the name of the reference entity; the trade date and the effective date; the (expected) maturity of the contract; the type of participating counterparties (dealer or end-user, and a finer classification of end-users as asset managers, banks, financial services, hedge funds, insurance companies, and "other"); and the executed notional amount. When anonymized, each counterparty is identified by a unique number that allows its positions to be tracked over time and across names. Each transaction is also specified as a new trade, an assignment of an existing trade, or a termination of an existing trade. The DTCC repository holds these details on the legal, or "gold," record for both cleared and bilateral CDS transactions. The repository also stores key information on market participants' single-sided, non-legally binding, or "copper" record for CDS transactions.

Most regulators around the world (e.g., the SEC in the US) are connected to the DTCC-TIW and have access to its information within the scope of their jurisdictional influence. For example, the SEC can access transaction information on single-name CDSs traded by US counterparties or written on a US reference entity. Regulators can examine and download DTCC-TIW data at any time, but these data are not updated in real-time. In most cases, they

\footnotetext{
${ }^{17}$ The banks and industry associations are: Bank of America, Barclays Capital, BNP Paribas, Citigroup, Credit Suisse, Deutsche Bank, Dresdner Kleinwort, Goldman Sachs, HSBC, JP Morgan Chase, Merrill Lynch, Morgan Stanley, Royal Bank of Scotland, Société Générale, UBS, and Wachovia, as well as the Managed Funds Association and the ISDA. Their letter can be accessed at: https://www.newyorkfed.org/medialibrary/media/newsevents/news/markets/2008/regulators letter.pdf.
} 
can also see the identity of the counterparties for the reported transactions, again within the scope of their jurisdictional influence. So far, the DTCC-TIW is the main source of "regulatory" transparency. Nevertheless, regulators are now moving towards direct electronic access to the transaction data stored by other SDRs.

Besides "regulatory" transparency, the DTCC also offers some degree of "market" transparency. For example, the repository publishes weekly reports on its website that summarize the current data on its gold record. This information consists of end-of-week aggregate data on the outstanding number of contracts and gross and net notional for the top 1,000 reference entities. In addition, the DTCC publishes the weekly number of traded contracts and amount of traded gross notional that represent a transfer of credit risk among the market participants for the top 1,000 reference entities. The DTCC public disclosure of the first type of information (position data) began on October 31, 2008. The DTCC public disclosure of the second type of information (market risk activity) began on August 13, 2010. The DTCC updates this online information for the previous week every Tuesday after 17:00 ET (22:00 GMT). The reporting "delay" is part of a confidentiality agreement between the DTCC and market participants in the single-name CDS market.

\section{A.2. Intercontinental Exchange Clear Credit}

In 2008, the hedge fund Citadel Group proposed to the Chicago Mercantile Exchange (CME) to set up a clearinghouse and an electronic trading system for CDS. The proposal quickly failed because of the opposition of major bank-dealers. The banks responded to Citadel's initiative by collaborating with ICE US Trust, one of CME's competitors, which was setting up its own clearinghouse. The banks attached a number of conditions to the partnership that gave them significant power at ICE's clearinghouse, in particular by maintaining a majority at the ICE risk committee, which sets the fees, prices, and margin requirements, and 
recommends which derivatives should be handled through the clearinghouse. Other favorable provisions to the banks were the restrictive membership rules that limited participation in the clearinghouse. Furthermore, in order to limit central clearing transparency, these founding banks required ICE to provide settlement price data exclusively to Markit, and to make them accessible to the public only after a fee payment (Norman, 2011, pp. 297-302).

Intercontinental Exchange Clear Credit (ICECC) is the first and only clearinghouse that currently clears US single-name CDS. The Federal Reserve approved ICECC (initially launched as ICE US Trust) to clear single-name CDS on March 4, 2009 and it quickly took off: by March 2010, it had cleared more than $\$ 71$ billion notional of CDS referencing 33 single names (Norman, 2011, pp. 297-302). At the end of 2013, ICECC had accepted for clearing 159 US corporate reference entities. ICECC has also seen a growing number of CDS clearing memberships from institutional and buy-side investors. ${ }^{18}$ The SEC's analysis of CDS trading activity from July 2012 to December 2013 indicates that, out of the $\$ 938$ billion notional traded in North American corporate single-name CDS, \$666 billion had characteristics making them suitable for clearing by ICECC. Approximately 79 percent of this, or $\$ 525$ billion, was actually cleared through ICECC. The fraction of total gross notional amount of new trades and assignments in North American single-name CDSs that were accepted for clearing by ICECC and were cleared within 14 days of the initial transaction ranges between 50 percent and 70 percent over the period 2011-2013. ${ }^{19}$ Before accepting a new CDS contract for clearing, ICECC looks at its weekly open interest and trading volume

\footnotetext{
${ }^{18}$ From January to May 2015, 12 firms were added to the 18 existing members. The list of clearing members can be found at https://www.theice.com/clear-credit/participants. "The US Securities and Exchange Commission (SEC) has approved an application by LCH's CDSClear unit for registration as a clearing agency. The authorisation, granted on December 29, 2016, allows LCH to begin clearing single-name credit default swap (CDS) contracts for US clients". "Demand for ICE's services has been hampered by the SEC's failure to mandate clearing of single-name CDS contracts. However, 25 large asset managers committed to begin voluntarily clearing their single-name CDS trades in late 2015 - a development that helped boost clearing volumes at ICE in 2016" (Devasabai, 2017).

${ }^{19}$ See https://www.sec.gov/rules/proposed/2015/34-74245.pdf (p. 129).
} 
on the DTCC Trade Information Warehouse (DTCC-TIW) and consults with the clearing members regarding the eligibility of the contract for central clearing.

Through its website, ICECC publicly disseminates end-of-day post-trade information on the open interest, volume, and number of transacted contracts for all single-name CDSs processed by its clearinghouse. Thus, while DTCC-TIW publishes single-name CDS open positions and trading activity only on a weekly basis and for top-reference entities, ICECC publishes data on all its cleared contracts at a daily frequency. These data can be accessed for free at https://www.theice.com/marketdata/reports/99, and they can help to track trading and clearing patterns in specific single-name CDSs, especially for high-volume trades, given that the daily number of transactions for each contract is relatively low.

Under the DFA (even while the SEC implementation is not yet effective), ICECC is obligated to report all of its cleared trades to an SDR for regulatory monitoring and public dissemination. ${ }^{20}$ Currently, ICECC reports all of its cleared trades to ICE Trade Vault, the SDR of ICE, on an intra-daily basis. Any regulator can require full access to ICE Trade Vault within the scope of its jurisdiction. Swap data repository participants can access their own data and the data that ICE Trade Vault makes publicly available (which do not include the identity of the trading counterparties). Finally, public users can access the publicly disclosed portion of the data for free after registering for an account on ICE Trade Vault's website. ${ }^{21}$ The information provided, besides the time stamp, size, and price of each trade, also includes the nature of the trade, whether the trade is cleared (and subject to collateralization), and whether the trade involves a large block. The historical data we have downloaded from ICE Trade Vault for the period considered, however, show that the real-time CDS trade reports available to public users contain only CDS index trades and no single-name CDS trades.

\footnotetext{
${ }^{20}$ The reporting to SDRs is already mandatory for cleared CDS index trades under the rules of the Commodity Futures Trading Commission.

${ }^{21}$ The ICE Trade Vault data can be accessed at https://www.icetradevault.com/tvus-ticker/.
} 